"Nursing home aversion post-pandemic: Implications for savings and long-term care policy"

Bertrand Achou, Philippe De Donder, Franca Glenzer, Minjoon Lee and Marie-Louise Leroux 


\title{
Nursing home aversion post-pandemic: Implications for savings and long-term care policy*
}

\author{
Bertrand Achou ${ }^{\dagger} \quad$ Philippe De Donder ${ }^{\ddagger} \quad$ Franca Glenzer ${ }^{\S} \quad$ Minjoon Lee $\mathbb{I}^{\mathbb{1}}$ \\ Marie-Louise Leroux"
}

September 7, 2021

\begin{abstract}
COVID-19 outbreaks at nursing homes during the recent pandemic, which received ample media coverage, may have lasting negative impacts on individuals' perceptions regarding nursing homes. We argue that this could have sizable and persistent implications for savings and long-term care policies. We first develop a theoretical model predicting that higher nursing home aversion should induce higher savings and stronger support for policies subsidizing home care. We further document, based on a survey on Canadians in their $50 \mathrm{~s}$ and $60 \mathrm{~s}$, that higher nursing home aversion is widespread: $72 \%$ of respondents are less inclined to enter a nursing home because of the pandemic. Consistent with our model, we find that the latter are much more likely to have higher intended savings for older age because of the pandemic. We also find that they are more likely to strongly support home care subsidies.
\end{abstract}

Keywords: Pandemic Risk, Nursing Home, Long-Term Care, Savings, Public Policy.

\footnotetext{
*This paper draws on research supported by the Social Sciences and Humanities Research Council (Grant 435-2020-0787) and by Fonds de Recherche du Québec-Société et Culture (Grant 2019-SE2-252890). De Donder acknowledges funding from ANR under grant ANR-17-EURE-0010 (Investissements d'Avenir program) and from the Chair "Marché des risques et création de valeurs, fondation du risque/Scor". We are grateful to David Boisclair and Julien Navaux for help with the survey. The usual disclaimer applies.

${ }^{\dagger}$ Retirement and Savings Institute, HEC Montréal, Montréal, Canada. E-mail: bertrand.achou@gmail.com

${ }^{\ddagger}$ Toulouse School of Economics, CNRS, University of Toulouse Capitole, Toulouse, France. E-mail: philippe.dedonder@tse-fr.eu

${ }^{\S}$ Retirement and Savings Institute, HEC Montréal, Montréal, Canada. E-mail: franca.glenzer@hec.ca

${ }^{\mathbb{I}}$ Department of Economics, Carleton University, Ottawa, Canada. E-mail: minjoon.lee@carleton.ca

"Département des Sciences Economiques, ESG-UQAM, Montréal, Canada; CESifo, Munich, Germany; CORE, Université catholique de Louvain, Louvain-la-Neuve, Belgium. E-mail: leroux.marie-louise@uqam.ca
} 


\section{Introduction}

In many countries including Canada and its provinces of Québec and Ontario, the recent COVID19 pandemic has shed light on the precarious sanitary conditions of the elderly population and, in particular, of those in nursing homes. There has been extensive media coverage of the dramatic consequences of COVID in nursing homes, with its population being the most hit by the pandemic. As we detail in Section 2, in the first wave (March to August 2020), more than $80 \%$ of the Canadian COVID deaths were reported in nursing and seniors' homes (Canadian Institute for Health Information, 2020). More generally, the pandemic has put nursing homes in the spotlight in terms of how they are managed (even before the pandemic hit), of their lack of staff and of the consequences of a pandemic on the living conditions of the dependent elderly in these facilities.

As a consequence, the pandemic has increased awareness of the population regarding their long-term care (hereafter LTC) needs in case they become dependent and may have affected permanently their preferences regarding future LTC solutions. ${ }^{1}$ The pandemic has then led policy makers and the population in general to think about alternative solutions to nursing home care. One alternative solution is to receive LTC at home. The main concern for the home-care option is its (out-of-pocket) costs. Home care is much more expensive than public nursing home care, in particular if dependents do not have family members that can provide informal care (see Section 2 where we compare the costs of nursing homes versus home care).

The pandemic has pushed society to reconsider the attractiveness of home versus nursing home care. Because individuals are planning today the financial resources they will need tomorrow in case they become dependent, they may wish to adapt their saving plans as well. In the same way, policy makers will need to develop better suited LTC policies. Those public solutions are multiple: build new nursing homes, foster the training of LTC workers, but also make the home care option more affordable through, for instance, subsidies and tax exemptions. ${ }^{2}$

Developing adequate LTC policies regarding the type of care provision and financing solutions is crucial. Indeed, in every developed countries, population is aging, implying that the fraction of people with very specific health needs is growing. According to OECD (2011), the fraction of people aged 80 and above is expected to grow from $4 \%$ of the total OECD population in 2010 to $10 \%$ in 2050. Canada is not exempt from this trend. For instance, Clavet et al. (2021) have estimated that the number of individuals needing help with activities of daily living (hereafter ADLs) in Québec is likely to almost double, from 315,000 in 2020 to more than 600,000 in 2050. If many households plan to use a more costly option of LTC post-pandemic, they will most likely

\footnotetext{
${ }^{1}$ LTC is defined as "the day-to-day help with activities such as washing and dressing, or help with household activities such as cleaning and cooking" (OECD, 2011). LTC often comes with additional type of support such as medical assistance. Individuals in need of LTC are called dependent.

${ }^{2}$ Those debates are not limited to the Canadian context that we study. For instance, increasing government spending on home health care to avoid reliance on nursing homes is currently debated in the US (see https: //www.nytimes.com/2021/08/26/briefing/biden-economy-package.html).
} 
need to save more in order to finance it. But this form of self-insurance is costly and it may call for increased policy intervention.

The objective of this paper is to provide empirical evidence on the potential impact of the recent COVID pandemic on LTC preferences, and on how these shifts in expected LTC choices result in changes in saving behavior and LTC policy preferences. The paper also provides a theoretical model highlighting the underlying mechanisms behind the changes caused by the pandemic.

The COVID pandemic can have two long term implications. First, people may believe in the possibility of a recurring pandemic and, they may also believe that a nursing home does not provide much protection against such risks. Second, it might have worsened individuals' view on nursing home care even in the absence of a pandemic, in the long-run, as they were confronted with more (negative) information about the quality of nursing home care. Our paper evaluates how preferences for home care or nursing home care may have been (durably) affected by the pandemic. In particular, we study, both theoretically and empirically, how a stronger preference for home care post-pandemic may have changed saving decisions and the support for a public policy promoting home care.

We propose a model where individuals differ in their preference for home care, or equivalently in their degree of aversion to nursing home. We assume, as observed empirically, that home care is more expensive than nursing home care. We first develop the model in the absence of any pandemic risk that could affect nursing home aversion. We show that those who plan to use home care, a more costly option than nursing home care, would choose to save more. We then introduce a pandemic risk which worsens the view on nursing home care. As highlighted previously, this results either from a higher (perceived) probability of catching a pandemicrelated disease in nursing homes, or from a higher degree of nursing home aversion reflecting new (negative) information about nursing home quality in general. In our framework, the two turn out to be isomorphic. We then show that, following a pandemic, a higher proportion of households prefer the home care option and that, in order to finance this choice, they choose to save more. We finally introduce public intervention taking the form of a home care subsidy, financed by taxation. We show that support for such a policy is likely to increase post-pandemic. We also show that the increase in support is across the board and not limited to those who were already in favor pre-pandemic.

We then confront these theoretical results to empirical findings. To do so, we have partnered in the fall 2020 with Asking Canadians, a Canadian online panel survey organization, to field a survey on the LTC-related preferences of the elderly. The survey was fielded to 3,004 Ontarian and Québec respondents. The survey targeted respondents between 50 and 69 years old, with the intention of learning people's LTC choices in the new normal after the current pandemic, instead of choices during the pandemic. The survey asked questions regarding how LTC preferences, saving behaviour and preferences for public policies were affected by the recent COVID 
pandemic.

The survey evidence is in line with the predictions of the theoretical model. We find a widespread increase in nursing home aversion post-pandemic: $72 \%$ of the sample report to be less inclined to enter a nursing home. Also, about $70 \%$ of the sample report that their view on the exposure to health risks in nursing homes worsened after the pandemic. At the same time, many respondents are aware that the home care option is more costly and hence, they would have to save more to finance that option. Consistent with our theoretical model, about a quarter of the sample report that they indeed plan to save more for old age because of COVID, and the vast majority of them say that these increased planned savings are intended to avoid entering a nursing home. We further confirm that this positive association between increased planned savings and increased nursing home aversion is robust to controlling for many potential confounding factors. Specifically, we find that increased nursing home aversion is associated with a higher probability of increased planned savings of 8.5 to 14.0 percentage points. This is sizable and corresponds to $31.6 \%$ to $52.0 \%$ of the unconditional (weighted) mean probability of 26.9\%. Overall, our results thus suggest that the pandemic may have a significant lasting effect on intended savings for old age because of increased nursing home aversion and thus increased willingness to rely on home care.

Lastly, we document a strong support for a policy that would subsidize home care with $70 \%$ of our sample either "very much agreeing" or "agreeing" with it. This suggests that such a policy could have broad electoral support. Furthermore, consistent with the predictions of our model, we find strong evidence that the increased support for such a policy post-pandemic is driven by increased nursing home aversion. Quantitatively, we find that increased nursing home aversion is associated with a higher probability to "very much agree" with such a policy of 7.3 to 11.8 percentage points. This corresponds to $36.1 \%$ to $58.4 \%$ of the unconditional (weighted) mean probability which is of $20.2 \%$.

Our paper is related to the following strands of the literature. The first one is the growing literature on the design of appropriate LTC insurance (LTCI) policies. So far, this literature has mostly concentrated on the reasons behind the existence of a "LTCI puzzle" (namely, the lack of private LTCI worldwide) and on how governments could incentivize LTCI purchase. ${ }^{3}$ There is also an expanding literature on the value of (partial) public insurance (De Nardi et al., 2016; Braun et al., 2017; Achou, 2020, to name a few). Most of these studies do not consider individuals' choices between nursing home care and home care (one exception is Koreshkova and Lee, 2020, who study these choices using a structural model). We contribute to this literature by first, proposing a theoretical model on how a pandemic can affect the relative preferences for the two LTC options, and second, by showing whether this is supported by empirical evidence. Our results then shed light on how to redesign public LTC policies post-pandemic. Our paper

\footnotetext{
${ }^{3}$ About the LTCI puzzle, see the surveys by Brown and Finkelstein (2009), OECD (2011) and, Pestieau and Ponthiere (2011).
} 
is also related to the literature on old-age savings as a form of self-insurance for late-in-life risks (e.g. Palumbo, 1999; Kopczuk and Lupton, 2007; De Nardi et al., 2010; Ameriks et al., 2011; Kopecky and Koreshkova, 2014; Lockwood, 2018; Ameriks et al., 2020). We contribute to this literature by showing that nursing home aversion due to the pandemic can increase the willingness to save for older ages.

Finally, our paper contributes to the recent and prolific literature on the effect of a pandemic, and specifically of the COVID-19, on different economic outcomes. That literature studies both micro (for instance, the costs and benefits of specific confinement measures) and macro (for instance, the effects of the pandemic on trade, labour markets and the economic activity in general) outcomes. ${ }^{4}$ Directly related to our paper, Hurwitz et al. (2021) seek to understand the potential long-run implications of the pandemic on savings for retirement. Yet, although the pandemic has hit primarily the (dependent) elderly and especially those in nursing homes, we are unaware of any specific analysis of the changes in preferences for home care and nursing home care, and of their impacts on savings and political support for home care post-pandemic. One exception is the survey conducted by the National Institute on Aging (2021) that asks questions similar to ours regarding the preferences of Canadians toward nursing home care and state intervention, as well as about their beliefs about health risk exposure and how they have changed due to pandemic. They find that $96 \%$ of the respondents who participated in the survey, aged 65 years and older, report that, as they get older, they will do everything they can to avoid moving into a nursing home and that $86 \%$ considered that LTC should be part of an integrated health system. Compared to this paper, our study provides a theoretical model that allows us to form sharp predictions on the impact of the pandemic on intended savings as well as on the support for a specific LTC policy (home-care subsidy). Then, we conduct an empirical analysis to demonstrate that nursing home aversion post-pandemic is indeed the main driving force behind the increase in intended savings and supports for such a policy.

Our paper is structured as follows. In the next section, we provide the institutional background regarding the organization of the LTC sector in Canada and how COVID affected this sector. In Section 3, we develop a theoretical model explaining individual choices of care, savings and preference for state intervention, both in the absence of a pandemic risk and then allowing for it. In Section 4, we describe our sample. In Section 5, we provide the empirical results obtained from our survey, regarding nursing home aversion, changes in intended savings, and support for a public policy promoting home care, following the COVID hit. The last section concludes.

\footnotetext{
${ }^{4}$ For instance, Gollier (2020) studies the costs and benefits of different strategies to lift lockdowns while Salanié and Treich (2020) compare public and private incentives for protection against the pandemic risk. Antras et al. (2020), Bonadio et al. (2021), Bricongne et al. (2021) study the impact of COVID on trade and globalisation, while Kahn et al. (2020), Cajner et al. (2020), and Kurmann et al. (2021) analyze its impact on labour markets and on firms.
} 


\section{The institutional background}

In this paper, we concentrate on individuals' choices for home care versus nursing home care, in case they face dependency. Our survey has asked a panel of 3,004 respondents, from Ontario and Québec, as to their preferences for these two options, taking into account the different features of home care and nursing home care. In this section, we provide an overview of the characteristics of each care option in Québec and Ontario.

We start by explaining the differences in prices paid by the elderly. If the dependent elderly enters a nursing home (private or public), the latter will provide services such as personal services (e.g. toileting and dressing), meal preparation, and nursing/medical services. In addition, it also provides basic (hygienic) goods and services so that, apart from the price paid for the nursing home, the elderly has to bear very few extra expenses.

The rates for a place in a nursing home vary across provinces. In Ontario, the maximum rates for an accommodation in a public nursing home are legally set by the Ministry of LongTerm Care and ranged, in 2019, from 1,891 CAD for a basic accommodation to 2,280 CAD for a semi-private room and $2,701 \mathrm{CAD}$ for a private one. These costs can be partly covered by a subsidy, whose maximum is 1,891 CAD per month and is conditional on individuals' financial situation. In particular, to be eligible for this subsidy, the elderly needs to be already receiving all provincial and federal benefits such as the Old Age Security (OAS), the Ontario Disability support program and the Guaranteed Income Security (GIS), and the subsidy will depend on their net income. ${ }^{5}$ In Québec, the setup is similar to that in Ontario. The prices of public nursing home care (also called CHSLD) depend on the type of accommodation, and range from 1,223 CAD (for a basic accommodation) to 1,642 CAD (for a semi-private room) and 1,966 CAD (for a private room). The program is means-tested and the out-of-pocket price for public nursing home care can be reduced depending on the financial situation (savings, home-ownership and monthly income) of the dependent elderly as well as on his marital status. ${ }^{6}$

One crucial issue with public nursing homes (both in Ontario and in Québec) is the significant delays between the time an individual is declared having issues with ADLs and the time she/he enters a public nursing home. Data on waiting times are relatively scarce. In Québec, in 2017, the waiting time was around 10 months, with a lot of variations across regions (Commissaire à la Santé et au Bien-être, 2017). In Ontario, according to the Waiting Time Alliance (WTA) report, the median waiting time was evaluated to be around 108 days in 2013-2014. ${ }^{7}$ As mentioned in a report of the Commission de la Santé et des Services Sociaux (2016) for Québec, these waiting times would have the undesirable consequence of pushing the elderly to enter a nursing home far away from their family and relatives. ${ }^{8}$

\footnotetext{
${ }^{5}$ See https://www. ontario.ca/page/get-help-paying-long-term-care

${ }^{6}$ See https://www.ramq.gouv.qc.ca/fr/citoyens/programmes-aide/hebergement-etablissement-public

${ }^{7}$ https://www . waittimealliance.ca/wp-content/uploads/2015/12/EN-FINAL-2015-WTA-Report-Card_ REV.pdf

${ }^{8}$ https://www.aqdr.org/wp-content/uploads/rapport-_chsld_16-06-07.recommandations_final.pdf
} 
For these reasons, the elderly dependent may instead choose to enter a private nursing home (not under agreement), for which there are usually no waiting times. ${ }^{9}$ In Québec, they range from 5,000 CAD to 8,000 CAD a month. ${ }^{10}$

Another alternative for the elderly facing issues with ADLs is to stay at home and to resort to home care. At-home services can take various forms such as meal preparation, personal services (e.g. toileting and dressing) and nursing services. Depending on the type of service required, the price of one hour of skilled nursing care varies between 15 CAD and 85 CAD in Québec, and between $23 \mathrm{CAD}$ and $70 \mathrm{CAD}$ in Ontario. ${ }^{11}$ Even if these services give rights to tax credits, home care can soon become disproportionately expensive. ${ }^{12}$ Take for example the situation of a dependent elderly who would require (only) 4 hours of care 7 days a week, the monthly cost of home care would be around 4,300 CAD if the cost of one hour of care is (only of) $35 \mathrm{CAD}$. This does not even take into account, that, in addition to the costs of home care services, the elderly, staying at home, will have to bear extra expenses such as food, hygienic products, clothes washing (expenses that are included in the rate of a nursing home). The individual will also have to bear additional expenses related to lodging such as house maintenance, mortgages, rents or electricity bills, which, by definition, are included in the nursing home rate. Importantly, while some policy programs help finance home care costs, they turn out to often cover only a small share of these costs. For instance, Tousignant et al. (2007) estimate that only $8 \%$ of home care needs are covered by the public system in Quebec. As a result, even more so than for the nursing home option, individuals relying on home care face huge out-of-pocket costs and so need to rely even more on dissaving, selling a home or using a reverse mortgage to finance LTC expenses. ${ }^{13}$ This is particularly the case as in Canada, like in many other OECD countries, private LTC insurance is almost nonexistent (see OECD, 2011 and Boyer et al., 2020).

Nonetheless, the pandemic may have made the home care option more attractive as, especially during the first wave, nursing homes experienced a large number of outbreaks and deaths both in Québec and Ontario. At the end of this first wave (May 2020), in Québec, more than $90 \%$ of the COVID deaths had occurred among individuals aged 70 and more, and around $70 \%$ of those deaths had occurred in nursing homes. ${ }^{14}$ Similarly, in Ontario, more than $70 \%$ of the COVID deaths by the end of May 2020 had occurred in nursing homes. ${ }^{15}$

\footnotetext{
${ }^{9}$ There are two types of private nursing homes. Those under agreement are privately managed but receive contributions from the government. As a result, they face the same rules and are imposed to charge the same fees as public nursing homes. From a patient viewpoint, they are thus very similar to public nursing homes. Those which are not under agreement do not receive contributions from the government and have more freedom regarding their operations (although they need a license) and the fees they can charge to residents. When we refer to private nursing homes, we thus refer to the latter type.

${ }^{10}$ https://bonjourresidences.com/blogue/couts-hebergement-chsld/

${ }^{11}$ These values were obtained from the Canadian Life and Health Insurance Association (CLHIA 2018).

${ }^{12}$ In Québec, the non-refundable tax credit lies between $20 \%$ and $35 \%$ of all LTC expenses, with a cap on the claimed amount of LTC expenses at home (see Revenu Québec, 2019).

${ }^{13}$ The reverse mortgage option is not very developed in Canada.

${ }^{14}$ Institut National de la Santé Publique du Québec.

${ }^{15}$ See https://covid-19.ontario.ca/data/long-term-care-homes for the cumulative number of COVID
} 
Many press releases reported that, in these nursing homes, some of the care takers left their jobs because they themselves had COVID, because of bad and unsafe working conditions, or because of work overload. ${ }^{16}$ This had the consequence of placing residents at increased risk by leaving them in bad living conditions (not bathed, not fed enough, and not medicated). For instance, in its report, the Protecteur du Citoyen (the ombudsman for Québec) mentions that $46 \%$ of the residents and $60 \%$ of their relatives reported that the quality of care decreased or was insufficient during the first wave, in particular for basic and hygienic care. ${ }^{17}$ At some nursing homes, appropriate health and satefy measures required for COVID patients have not been taken, which led to many COVID deaths. ${ }^{18}$

Finally, in this work, we do not consider the choice between public and private nursing homes for two reasons. First, prior to the pandemic, several professionals from the LTC sector that we consulted told us that there is no clear evidence that private nursing homes offer a better quality of care than public ones. Instead, as mentioned above, the main difference they highlighted was related to waiting times and location choices. Second, both in Québec and Ontario, the pandemic affected strongly both private and public nursing homes, and quality shortages were not confined to public nursing homes. ${ }^{19}$ As a consequence, we do not expect the pandemic to increase the attractiveness of private nursing homes relative to public ones, which is indeed verified by responses to our survey (see Section 5). Instead, given that both public and private nursing homes experienced a large number of COVID outbreaks in the first wave and that the press reported quality shortages in both types of institutions, we focus on the choice between home and nursing home care.

\section{The model}

We model a two-period setting. In the first period, all agents have the same endowment, and choose how much to save for the second period, with saving being their only source of income. All agents face two risks that may realize or not at the beginning of the second period of their life: (i) dependency and (ii) catching a disease associated with a possible future pandemic, which can be seen as being similar to COVID in 2020. Agents are homogeneous in both the probability of dependency and of catching the disease. The only decision to be taken in the second period is

deaths at Ontarian nursing homes by date and see https://covid-19.ontario.ca/data for the total cumulative number of COVID deaths in Ontario by date.

${ }^{16}$ From March to May 2020, infections among staffs at nursing homes and residential homes represented more than $10 \%$ of Canada's total cases (Canadian Institute for Health Information, 2020).

${ }^{17}$ See https://protecteurducitoyen.qc.ca/sites/default/files/pdf/rapports_speciaux/ rapport-etape-premiere-vague-covid-19-chsld.pdf

${ }^{18}$ See for instance, press releases about CHSLD Le Herron, in Québec.

${ }^{19}$ For an example of a negative press coverage during the pandemic about private nursing homes, see for instance: https://www.lapresse.ca/actualites/2021-03-16/chsld-prives-non-conventionnes/ quebec-doit-serrer-la-vis.php. 
for dependent agents to choose whether they prefer home care (HC, hereafter in this section) or moving to a nursing home ( $\mathrm{NH}$, hereafter in this section), which we call the care type decision. ${ }^{20}$

For pedagogical reasons, we first develop the model in the absence of a pandemic-risk in Section 3.1. This allows us to look at the determinants of the choice between $\mathrm{HC}$ and $\mathrm{NH}$, in the absence of a pandemic risk. We then introduce the pandemic risk in the model in Section 3.2 , in order to see how it affects both the saving and the care type decisions of the elderly. Finally, in Section 3.3, we introduce a social insurance program that would subsidize HC. We study how the perceptions (of costs and of probabilities of catching the disease as a function of care type, such as the relatively higher pandemic risk in NH shown in Section 2) affect the care type preferences, saving decisions as well as the preferences for public insurance.

\subsection{The model with no pandemic risk}

Agents all have the same endowment $W$ in the first period. In the first period, they choose how much to save, denoted by $s$, and in the second period, if they become dependent, whether to use $\mathrm{HC}\left(\mathbb{1}_{H C}=1\right)$ or $\mathrm{NH}\left(\mathbb{1}_{H C}=0\right)$. To simplify (and without loss of generality for our results), we assume away any discounting between the two periods, as well as any real return on saving. Agents all face the same probability $p$ of becoming dependent at the beginning of the second period.

At the beginning of the first period, agents' expected utility is given by

$$
u_{1}(W-s)+(1-p) u(s)+p\left[\mathbb{1}_{H C} v_{H C}(s)+\left(1-\mathbb{1}_{H C}\right) v_{N H}(s)\right]
$$

where $u_{1}(x)$ denotes the first-period utility function, $u(x)$ the second-period utility function in case of good health, and $v_{j}(x)$ with $j=\{N H, H C\}$ the utility function of dependent agents as a function of their care type choice. All utility functions are increasing and (weakly) concave in consumption $x$. The function $u($.$) also satisfies the Inada condition that \lim _{x \rightarrow 0} u^{\prime}(x) \rightarrow+\infty$.

We assume that the type of care affects individual preferences in two directions. First, each type of care is associated with an out-of-pocket cost for the dependent agent, denoted by $L_{j}{ }^{21}$ In the following, relying on the empirical evidence presented in Section 2, we assume that the out-of-pocket cost of $\mathrm{HC}$ is higher than the out-of-pocket cost of $\mathrm{NH}$, that is $L_{H C}>L_{N H}$. We also assume that $W>L_{H C}>L_{N H}{ }^{22}$

\footnotetext{
${ }^{20}$ We assume that households do not have private LTC insurance. As already mentioned in Section 2, very few people purchase private LTCI (the so-called LTCI puzzle). Also, we do not make the distinction between private and public nursing homes in studying the care type decision. Implicitly, we assume that the default NH option is the public one given its lower cost and apparently-equivalent quality relative to its private counterpart.

${ }^{21}$ Any existing social LTCI (such as subsidies or tax credits) covering LTC expenses is already embedded here, since we consider out-of-pocket expenses. The important assumption here is that the amount of social LTCI is exogenously set.

${ }^{22}$ In our model, for simplicity, there is just one intensity of care needs if dependent. The main intuitions would hold if we assumed instead a distribution of intensity of care needs conditional on being dependent inducing a distribution for the cost of $\mathrm{HC}, L_{H C}\left(L_{N H}\right.$ is not a function of the severity of care needs in the public $\mathrm{NH}$ considered here). In that case, the LTC choice in the second period would be characterized by a probability of
} 
Second, agents differ in their intrinsic preference for $\mathrm{HC}$ vs $\mathrm{NH}$. We model this by using an additive term $\theta$ to the utility obtained with $\mathrm{HC}$, so that the utility functions are such that

$$
\begin{aligned}
& v_{N H}(x)=u\left(x-L_{N H}\right), \\
& v_{H C}(x)=u\left(x-L_{H C}\right)+\theta .
\end{aligned}
$$

Agents are aware of their type, defined by their value of $\theta$, while the econometrician does not observe each individual $\theta$ 's value, but instead knows that $\theta$ is distributed over $\left[0, \theta_{\max }\right]$ according to distribution function $f(\theta)$ and cumulative distribution $F(\theta)$.

Together, these assumptions imply the following ranking of marginal utilities: ${ }^{23}$

$$
v_{H C}^{\prime}(x)>v_{N H}^{\prime}(x)>u^{\prime}(x) .
$$

Agents have to choose $s$ (in the first period) and $I_{H C} \in\{0,1\}$ (at the beginning of the second period) to maximize their expected utility. We solve this problem in two steps. First, agents decide how much to save conditional on each care type. Second, they compare their utility levels in $\mathrm{HC}$ and $\mathrm{NH}$, and choose the best among the two options.

Their preferred level of $s_{j}^{*}$ maximizes the expected utility under each care option $j=$ $\{N H, H C\}$ :

$$
\max _{s} E U_{j}=u_{1}(W-s)+(1-p) u(s)+p v_{j}(s) .
$$

Defining first-period consumption as $c=W-s$, the first-order condition (hereafter, FOC) with respect to $s$ is:

$$
\frac{\partial E U_{j}}{\partial s}=-u_{1}^{\prime}(c)+(1-p) u^{\prime}(s)+p u^{\prime}\left(s-L_{j}\right)=0,
$$

which depends on the type of care chosen, $j=\{N H, H C\}$. Under the Inada condition $\left(u^{\prime}(0) \rightarrow\right.$ $\infty)$, we always have $s^{*}>0$.

It is straightforward to see that a higher $L_{j}$ increases the marginal benefit from saving, so that $s_{H C}^{*}>s_{N H}^{*}$ when $L_{H C}>L_{N H}$.

Let us now find how agents make their choice between NH and HC. They will choose HC over NH if:

$$
\begin{aligned}
V_{H C}(\theta) & =u_{1}\left(W-s_{H C}^{*}\right)+(1-p) u\left(s_{H C}^{*}\right)+p\left(u\left(s_{H C}^{*}-L_{H C}\right)+\theta\right) \\
>V_{N H} & =u_{1}\left(W-s_{N H}^{*}\right)+(1-p) u\left(s_{N H}^{*}\right)+p u\left(s_{N H}^{*}-L_{N H}\right),
\end{aligned}
$$

where $s_{j}^{*}$ is defined by (2).

using each option conditional on being dependent. The main intuitions from our model would apply in such a framework.

${ }^{23}$ This relationship (i.e. higher marginal utility under dependency than under autonomy) is quite standard in the literature. See, among others, Courbage and Eeckhoudt (2012), Cremer and Pestieau (2014), De Donder and Leroux (2013), Canta et al. (2016), De Donder and Pestieau (2017), Klimaviciute and Pestieau (2018), Courbage and Montoliu-Montes (2018), Ameriks et al. (2020), Leroux and Pestieau (2020). 
Denote $\Delta V(\theta)=V_{H C}(\theta)-V_{N H}$. Note first that $\Delta V(0)<0$ since $L_{H C}>L_{N H}$ (even if agents can adapt their saving level, it is easy to see that utility decreases with $L_{j}$ ). Moreover, since $\Delta V(\theta)$ increases with $\theta$, we denote by $\hat{\theta}$ the type of the agent indifferent between $\mathrm{HC}$ and NH. ${ }^{24}$ It satisfies $\Delta V(\hat{\theta})=0$ or equivalently,

$$
\begin{aligned}
p \hat{\theta}= & u_{1}\left(W-s_{N H}^{*}\right)-u_{1}\left(W-s_{H C}^{*}\right)+(1-p)\left(u\left(s_{N H}^{*}\right)-u\left(s_{H C}^{*}\right)\right) \\
& +p\left(u\left(s_{N H}^{*}-L_{N H}\right)-u\left(s_{H C}^{*}-L_{H C}\right)\right) .
\end{aligned}
$$

Hence, all agents with $\theta<\hat{\theta}$ (resp., $\theta>\hat{\theta}$ ) prefer NH to HC (resp., the opposite). We then obtain that: ${ }^{25}$

$$
\begin{aligned}
\frac{\partial \hat{\theta}}{\partial L_{N H}} & =-u^{\prime}\left(s_{N H}^{*}-L_{N H}\right)<0, \\
\frac{\partial \hat{\theta}}{\partial L_{H C}} & =u^{\prime}\left(s_{H C}^{*}-L_{H C}\right)>0 .
\end{aligned}
$$

Hence, an increase in $L_{N H}$ (resp. in $L_{H C}$ ) moves $\hat{\theta}$ to the left (resp. to the right) so that fewer (resp. more) individuals choose to enter a nursing home.

Observe also that:

$$
\frac{\partial \hat{\theta}}{\partial W}=\frac{1}{p}\left[u_{1}^{\prime}\left(W-s_{N H}^{*}\right)-u_{1}^{\prime}\left(W-s_{H C}^{*}\right)\right] \leq 0,
$$

because additional income increases the utility with $\mathrm{HC}$ more than that with $\mathrm{NH}$ (since $s_{H C}^{*}>$ $s_{N H}^{*}$ implies a smaller first-period consumption level in $\mathrm{HC}$ ). An exogenous increase in income then increases the number of agents choosing $\mathrm{HC}$ over $\mathrm{NH}$, everything else constant. ${ }^{26}$

The results of this section are summarized below:

Proposition 1. In the absence of a pandemic risk, individuals save more if they want to use $\mathrm{HC}$ rather than $\mathrm{NH}$ in case they become dependent.

An increase in the cost of nursing home care, $L_{N H}$ (resp. home care, $L_{H C}$ ) increases (resp. decreases) the number of individuals resorting to home care.

\subsection{Introducing a pandemic risk}

We now introduce a pandemic risk, and see how it impacts individual choices. This pandemic can be seen as being similar to the COVID pandemic in the sense that, as it was observed in Canada (see Section 2), it is likely to hit more severely individuals in $\mathrm{NH}$.

This pandemic risk is associated with a utility $\operatorname{cost} C$ for the person who catches the disease. This assumption seems more in line with the intuition than a monetary cost. Also, Canada

\footnotetext{
${ }^{24}$ We implicitly assume that the maximum value of $\theta, \theta_{\max }$, is large enough that $\Delta V\left(\theta_{\max }\right)>0$ so that some people prefer $\mathrm{HC}$, in accordance with reality.

${ }^{25}$ In the following, when applicable, we use of the envelop theorem for $s_{N H}^{*}$ and $s_{H C}^{*}$.

${ }^{26}$ In Section 3.3, we introduce the assumption that the first-period utility is linear in consumption, so that $u_{1}(x)=x$. In that case, income $W$ has no impact on the decision to choose HC over NH.
} 
(as most advanced countries) has a social health insurance system that covers most if not all pandemic-related health expenditures, so that the out-of-pocket cost of the pandemic disease is in general low. Agents rather fear the risk of complications and of dying, which is better represented as an (non insurable) utility cost.

Agents all face the same probability $p_{C}$ of catching the disease if either not dependent or in HC. ${ }^{27}$ We open up the possibility that this probability is larger in $\mathrm{NH}$, and equal to $\beta p_{C}$ with $\beta>1$. Note that what we care about is the individuals' perceived probability of risk exposure in $\mathrm{NH}$, as this is what will drive their preference for care type (and for saving). As explained in Section 2, the press has largely disseminated the idea that NH was not a safe environment, at least during the first COVID wave, and that the elderly in these facilities were particularly at risk of infection (evidence indeed showed that infection rates in $\mathrm{NH}$ were much higher than in the rest of the population). For that reason, it seems reasonable to assume that agents perceive the risk of catching the disease as being higher in $\mathrm{NH}$ than at home, and to set $\beta>1$. We assume that the probabilities $p$ and $p_{C}$ are independent from each other.

Agents' ex ante expected utility is then given by:

$$
\begin{aligned}
E U_{j}= & u_{1}(W-s)+(1-p)\left[\left(1-p_{C}\right) u(s)+p_{C}(u(s)-C)\right] \\
& +p\left[\left(1-p_{C, j}\right) v_{j}(s)+p_{C, j}\left(v_{j}(s)-C\right)\right] \\
= & u_{1}(W-s)+(1-p)\left[u(s)-p_{C} C\right]+p\left[v_{j}(s)-p_{C, j} C\right],
\end{aligned}
$$

where $p_{C, H C}=p_{C}$ and $p_{C, N H}=\beta p_{C}$. The FOC with respect to $s$ with care type $j \in\{H C, N H\}$ is

$$
\frac{\partial E U_{j}}{\partial s}=-u_{1}^{\prime}(c)+(1-p) u^{\prime}(s)+p u^{\prime}\left(s-L_{j}\right)=0 .
$$

This is the same FOC as without a pandemic risk, and we thus have that $s_{H C}^{*}>s_{N H}^{*}>0$ since $L_{H C}>L_{N H}$. This means that, for a given choice of care, neither $\beta$ nor $C$ has an impact on saving levels.

Agents choose $\mathrm{HC}$ over $\mathrm{NH}$ if:

$$
\begin{aligned}
V_{H C}(\theta) & =u_{1}\left(W-s_{H C}^{*}\right)+(1-p)\left[u\left(s_{H C}^{*}\right)-C p_{C}\right] \\
& +p\left[u\left(s_{H C}^{*}-L_{H C}\right)-C p_{C}+\theta\right] \\
>V_{N H} & =u\left(W-s_{N H}^{*}\right)+(1-p)\left[u\left(s_{N H}^{*}\right)-C p_{C}\right] \\
& +p\left[u\left(s_{N H}^{*}-L_{N H}\right)-\beta C p_{C}\right],
\end{aligned}
$$

where $s_{j}^{*}$ is defined by (3). We then obtain that the threshold type, $\hat{\theta}$, is given by $\Delta V(\hat{\theta})=0$, so that

$$
\begin{aligned}
p \hat{\theta}= & u_{1}\left(W-s_{N H}^{*}\right)-u_{1}\left(W-s_{H C}^{*}\right)+(1-p)\left[u\left(s_{N H}^{*}\right)-u\left(s_{H C}^{*}\right)\right] \\
& +p\left[u\left(s_{N H}^{*}-L_{N H}\right)-u\left(s_{H C}^{*}-L_{H C}\right)+(1-\beta) C p_{C}\right],
\end{aligned}
$$

\footnotetext{
${ }^{27}$ Note that we could assume that, for those living in the community (as opposed to a nursing home), the risk of catching the disease $\left(p_{C}\right.$ and $\left.C\right)$ is different depending on whether the individual is healthy or dependent. Our results would remain qualitatively unchanged, at the cost of a more cumbersome notation.
} 
and with all agents $\theta<\hat{\theta}$ (resp., $\theta>\hat{\theta}$ ) preferring $\mathrm{NH}$ to $\mathrm{HC}$ (resp., the opposite). Note that an increase in the pandemic risk, through either higher $\beta, C$ or $p_{C}$, is isomorphic to an increase in $\theta$.

Like in the previous section, we find that an increase in $L_{N H}$ (resp. in $L_{H C}$ ) decreases (resp., increases) $\hat{\theta}$. An increase in endowment weakly increases the number of individuals choosing HC. In addition,

$$
\begin{aligned}
\frac{d \hat{\theta}}{d \beta} & =-C p_{C}<0, \\
\frac{d \hat{\theta}}{d C} & =(1-\beta) p_{C}<0 \\
\frac{d \hat{\theta}}{d p_{C}} & =(1-\beta) C<0 .
\end{aligned}
$$

In words, increasing either the health cost of the disease $C$ or the relative exposure to a pandemic in $\mathrm{NH}$ compared to $\mathrm{HC}(\beta)$ makes $\mathrm{NH}$ less palatable so that $\hat{\theta}$ decreases. Note that $\hat{\theta}$ decreases with $p_{C}$ as well (since the impact of a higher $p_{C}$ is larger in $\mathrm{NH}$ than in $\mathrm{HC}$ ).

Proposition 2. When there exists a pandemic risk, an increase in (i) the baseline probability, $p_{C}$, of catching the disease, (ii) the perceived additional risk exposure to the pandemic in $N H, \beta$, and (iii) the utility cost, $C$, associated with the disease all decrease the number of agents willing to use the NH option, and increase the savings of those who switch from $\mathrm{NH}$ to $\mathrm{HC}$, from $\mathrm{s}_{\mathrm{NH}}^{*}$ to $s_{H C}^{*}$.

Before going further let us note an interesting feature of our model, resulting from the isomorphism between a positive shock to $\theta$ and an increase in the expected cost of the disease associated with $\mathrm{NH}, p_{C} \beta C$. There are two different stories regarding the impact of the current pandemic on the choice of care in the future. The first is that, for a given distribution of the $\theta \mathrm{s}$, a higher perceived risk of catching the disease under a potential future pandemic pushes individuals to switch from NH to HC. The second story highlights that as people are exposed more to (negative) information on $\mathrm{NH}$ during the current pandemic, it may impact permanently their preference for $\mathrm{NH}$ even if they do not fear a new pandemic in the future.

In that sense, $\mathrm{NH}$ aversion (or the increased preference for $\mathrm{HC}$ ) can be modeled either by an increase in the perceived expected cost of the disease (through higher $\beta, C$ or $p_{C}$ ), or by a shock on the preference $\theta$ for HC. All have the same implications in terms of savings and also in terms of support for public policy for HC (see below).

\subsection{Introducing a public subsidy for $\mathrm{HC}$}

Let us assume now that the government considers introducing a policy which would provide a benefit $P$ to agents choosing HC. It is financed by a lump-sum tax $T$ on all individuals in the 
first period. We assume throughout that $L_{H C}-L_{N H}>P>0$ so that the transfer partially compensates the extra cost of HC.

The reason why we consider a public policy directly targeted toward $\mathrm{HC}$ is related to the fact that the public system covers only a very small share of home care needs. As a result, to cover their care needs, individuals would face a much higher out-of-pocket cost for HC (even after tax credits) than for NH (see Section 2). The recent COVID pandemic has amplified the urge to find solutions that would make $\mathrm{HC}$ more affordable.

In case of $\mathrm{HC}$ choice, the individual maximizes the following expected utility function,

$$
E U_{H C}=u_{1}(W-s-T)+(1-p) u(s)+p\left[u\left(s+P-L_{H C}\right)+\theta\right]-C p_{C} .
$$

Using backward induction, we solve first for the optimal saving level, and then we study the individuals' preferences over the public policy.

We now introduce the following assumption, for the sake of simplicity:

Assumption 1. $u_{1}(x)=x$.

The level of savings, $s_{H C}^{*}$ satisfies: $^{28}$

$$
\frac{\partial E U_{H C}}{\partial s}=-1+(1-p) u^{\prime}(s)+p u^{\prime}\left(s+P-L_{H C}\right)=0 .
$$

For those who plan on using HC, under Assumption 1, the amount of saving is not affected by the tax $T$ but decreases with the subsidy $P$. We then denote it by $s_{H C}^{*}(P)$.

For agents choosing $\mathrm{NH}$, the problem is now to maximize:

$$
E U_{N H}=u_{1}(W-s-T)+(1-p) u(s)+p u\left(s-L_{N H}\right)-C p_{C}(1+p(\beta-1)) .
$$

Under Assumption 1, the level of savings, $s_{N H}^{*}$ satisfies

$$
\frac{\partial E U_{N H}}{\partial s}=-1+(1-p) u^{\prime}(s)+p u^{\prime}\left(s-L_{N H}\right)=0,
$$

which is affected neither by $T$ nor by $P$.

Agents choose HC over NH if:

$$
\begin{aligned}
V_{H C}(\theta)= & u_{1}\left(W-s_{H C}^{*}(P)-T\right)+(1-p) u\left(s_{H C}^{*}(P)\right)+p u\left(s_{H C}^{*}(P)+P-L_{H C}\right)-C p_{C}+p \theta \\
> & V_{N H}=\quad u_{1}\left(W-s_{N H}^{*}-T\right)+(1-p) u\left(s_{N H}^{*}\right)+p u\left(s_{N H}^{*}-L_{N H}\right)-C p_{C}(1+p(\beta-1)),
\end{aligned}
$$

\footnotetext{
${ }^{28}$ The solution is always interior $\left(s_{j}^{*}>0 \forall j=\{H C, N H\}\right)$ thanks to the Inada condition for the function $u(x)$. Note that we do not impose explicitly that the first period consumption must be positive, as this would complicate the analysis without bringing any new insight.
} 
where $s_{j}^{*}$ is defined by (5) and (7). We then obtain that the threshold for the indifference between $\mathrm{HC}$ and $\mathrm{NH}$ is given by $\Delta V(\hat{\theta})=0$, so that

$$
\begin{aligned}
p \hat{\theta}= & u_{1}\left(W-s_{N H}^{*}-T\right)-u_{1}\left(W-s_{H C}^{*}(P)-T\right)+(1-p)\left[u\left(s_{N H}^{*}\right)-u\left(s_{H C}^{*}(P)\right)\right] \\
& +p\left[u\left(s_{N H}^{*}-L_{N H}\right)-u\left(s_{H C}^{*}(P)+P-L_{H C}\right)+(1-\beta) C p_{C}\right] \\
= & s_{H C}^{*}(P)-s_{N H}^{*}+(1-p)\left[u\left(s_{N H}^{*}\right)-u\left(s_{H C}^{*}(P)\right)\right] \\
& +p\left[u\left(s_{N H}^{*}-L_{N H}\right)-u\left(s_{H C}^{*}(P)+P-L_{H C}\right)-C p_{C}(\beta-1)\right]
\end{aligned}
$$

where the second line is obtained by making use of Assumption 1. We see that this utility differential does not depend on $T$, which has to be paid no matter the care type choice. This equality then defines the threshold $\hat{\theta}(P)$ as a function of the policy instruments, and with all agents with $\theta<\hat{\theta}(P)$ (resp., $\theta>\hat{\theta}(P)$ ) preferring NH to HC (resp., the opposite), given $P$. We then have, using the envelope theorem for $s_{H C}^{*}(P)$,

$$
\frac{\partial \hat{\theta}}{\partial P}=-p u^{\prime}\left(s_{H C}^{*}(P)+P-L_{H C}\right)<0 .
$$

Intuitively, when $P$ increases, more people wish to use $\mathrm{HC}$ as its net cost is decreased, and $\hat{\theta}$ decreases. The intensity of that relationship depends on the magnitude of the risk of becoming dependent, i.e. $p$.

Note finally that, as before, any increase in the expected extra cost of the pandemic in $\mathrm{NH}$, i.e. in $(\beta-1) p_{c} C$, decreases $\hat{\theta}$, and thus, increases the number of people who would prefer to avoid $\mathrm{NH}$.

\subsection{Individual preferences for the public policy}

In this section, we assume that agents are proposed an exogenous policy $(T, P)$ and we look first at (i) who favors the introduction of this policy, and (ii) how this preference is affected by (changes in) the perceived pandemic risks.

\subsubsection{Political support for the HC policy}

It is obvious that an agent who would prefer $(T, P)$ to $(0,0)$ chooses $\mathrm{HC}$ rather than NH with $(T, P)$ (otherwise, in NH he/she would pay a tax and receive no transfer, and would be better off without the policy).

Let us assume for the moment that, in the absence of the policy $(T, P)$, the best option of an agent with $\theta$ would be to go to NH. This means that, for this agent, $\theta<\hat{\theta}(0)$, where the latter is defined as in equation (8) with $P=0$.

Such an agent would then be in favor of the introduction of the policy $(T, P)$ if

$$
\begin{aligned}
& W-s_{N H}^{*}+(1-p) u\left(s_{N H}^{*}\right)+p u\left(s_{N H}^{*}-L_{N H}\right)-C p_{C}(1+p(\beta-1)) \\
< & W-s_{H C}^{*}(P)-T+(1-p) u\left(s_{H C}^{*}(P)\right)+p u\left(s_{H C}^{*}(P)-L_{H C}+P\right)-C p_{C}+p \theta,
\end{aligned}
$$


so that the agent with $\tilde{\theta}$ such that

$$
\begin{aligned}
& p \tilde{\theta}=\left(s_{H C}^{*}(P)-s_{N H}^{*}\right)+T+(1-p)\left(u\left(s_{N H}^{*}\right)-u\left(s_{H C}^{*}(P)\right)\right) \\
& +p\left[u\left(s_{N H}^{*}-L_{N H}\right)-u\left(s_{H C}^{*}(P)-L_{H C}+P\right)-C p_{C}(\beta-1)\right],
\end{aligned}
$$

where $s_{H C}^{*}(P)$ and $s_{N H}^{*}$ are defined by (5) and (7) respectively, is indifferent between the two. All individuals with $\theta<\tilde{\theta}(T, P)$ prefer (NH with) $T=P=0$, while all with $\theta>\tilde{\theta}(T, P)$ prefer (HC with) $(T, P)$. This threshold decreases in the extra cost of the pandemic in NH, i.e. in $(\beta-1) p_{c} C$.

Note the difference between $\hat{\theta}(P)$ and $\tilde{\theta}(T, P)$. The threshold $\hat{\theta}(P)$ determines who prefers $\mathrm{HC}$ to $\mathrm{NH}$ in the presence of a policy $(T, P)$. It is the choice made in the last stage of the game, when $(T, P)$ has already been imposed. The threshold $\tilde{\theta}(T, P)$ rather determines who favors (or not) the policy $(T, P)$, in the case where this individual prefers $\mathrm{NH}$ to $\mathrm{HC}$ in the absence of the policy. This explains why $\tilde{\theta}$ is a function of $T$ (which is paid only in one branch of the comparison) while $\hat{\theta}$ is not (since it is paid in both branches).

It remains to be checked that $\tilde{\theta}(T, P)<\hat{\theta}(0)$. This condition is equivalent to

$$
\begin{aligned}
T< & s_{H C}^{*}(0)-s_{H C}^{*}(P) \\
& +(1-p)\left[u\left(s_{H C}^{*}(P)\right)-u\left(s_{H C}^{*}(0)\right)\right] \\
& +p\left[u\left(s_{H C}^{*}(P)-L_{H C}+P\right)-u\left(s_{H C}^{*}(0)-L_{H C}\right)\right],
\end{aligned}
$$

which is true if $T$ is small enough or $P$ is large enough. ${ }^{29}$ The condition is intuitive. An agent with a value of $\theta$ low enough to prefer $\mathrm{NH}$ over $\mathrm{HC}$ in the absence of a social program (i.e. with $\theta$ below $\hat{\theta}(0)$ ) requires the program to be generous enough (small tax and/or large transfer) to favor this policy (and move to HC to benefit from it).

To summarize the analysis so far, the support for an exogenous $(T, P)$ among those with $\theta<\hat{\theta}(0)$ is given by: $F(\hat{\theta}(0))-F(\tilde{\theta}(T, P))$ if condition (11) is satisfied, and by zero otherwise.

Assuming that the condition is satisfied, the derivative of the political support for $(T, P)$ with respect to the utility cost of the disease, $C$ (among those who prefer NH in the absence of policy) is given by:

$$
f(\hat{\theta}(0)) \frac{\partial \hat{\theta}(0)}{\partial C}-f(\tilde{\theta}(T, P)) \frac{\partial \tilde{\theta}(T, P)}{\partial C}=-p_{C}(\beta-1)[f(\hat{\theta}(0))-f(\tilde{\theta}(T, P))] \gtreqless 0
$$

so that it is not clear whether an increase in $C$ increases or decreases the support for the policy, among those who initially preferred the $\mathrm{NH}$ option. Note that the first term on the right-hand side, $-p_{C}(\beta-1) f(\hat{\theta}(0))$, is the marginal density of those who switch from $\mathrm{NH}$ to $\mathrm{HC}$ when facing a higher pandemic risk, even in the absence of the subsidy. The second term, $p_{C}(\beta-1) f(\tilde{\theta}(T, P))$, is the marginal density of those who become in favor of the policy but who

\footnotetext{
${ }^{29}$ Using the envelope theorem for $s_{H C}^{*}(P)$, we can prove that the RHS of $(11)$ increases with $P$. Note that this assumption is satisfied if the social program $(T, P)$ is actuarially fair.
} 
would have still chosen $\mathrm{NH}$ in the absence of the subsidy. So, assuming for instance a uniform distribution, this expression becomes null so that the support for $(T, P)$ among the agents who prefer $\mathrm{NH}$ when there is no policy, is independent of $C$ (equivalently, also independent of $p_{c}$ or $\beta)$.

Note that, if condition (11) is not satisfied, it means that the program proposed is not generous enough to attract the favor of those who prefer $\mathrm{NH}$ in the absence of the program.

We now turn to those individuals with $\theta>\hat{\theta}(0)$. Such agents would then be in favor of the introduction of the policy $(T, P)$ if:

$$
\begin{aligned}
& W-s_{H C}^{*}(0)+(1-p) u\left(s_{H C}^{*}(0)\right)+p u\left(s_{H C}^{*}(0)-L_{H C}\right)-C p_{C}+p \theta \\
< & W-s_{H C}^{*}(P)-T+(1-p) u\left(s_{H C}^{*}(P)\right)+p u\left(s_{H C}^{*}(P)-L_{H C}+P\right)-C p_{C}+p \theta,
\end{aligned}
$$

which corresponds exactly to condition (11).

If this condition is satisfied, then all agents with $\theta>\hat{\theta}(0)$ are in favor of $(T, P)$. Once more, the policy has to be generous enough to attract some support. But in this case, the specific value of the individual preference for $\mathrm{HC}, \theta$, plays no role (provided of course that $\theta>\hat{\theta}(0)$ ) since those agents compare two situations (with and without the program) where they anyway prefer $\mathrm{HC}$ to $\mathrm{NH}$.

If condition (12) (or equivalently, condition (11)) is satisfied, then the support for $(T, P)$ among those agents who initially preferred HC, is given by $1-F(\hat{\theta}(0))$ and its derivative with respect to $C$ is given by:

$$
-f(\hat{\theta}(0)) \frac{\partial \hat{\theta}(0)}{\partial C}=p_{C}(\beta-1) f(\hat{\theta}(0))>0 .
$$

More agents then prefer $\mathrm{HC}$ with public policy $(T, P)$ as $C$ (or $p_{C}$ or $\beta$ ) increases.

If condition (12) is not satisfied, then the policy $(T, P)$ has no support (neither among those with $\theta<\hat{\theta}(0)$ nor among those with $\theta>\hat{\theta}(0))$.

We then have two possible cases, depending on whether (11) is satisfied or not. In the following proposition, we sum up the above findings and show how the support within the entire population changes when the expected cost of the pandemic increases.

Proposition 3. (i) If $T$ is small enough compared to $P$ that (11) is satisfied, then the fraction of agents in favor of $(T, P)$ is given by:

$$
S(T, P)=1-F(\tilde{\theta}(T, P)),
$$

and increases with $C$ (as well as with $\beta$ and $p_{C}$ ) since:

$$
\frac{\partial S(T, P)}{\partial C}=-f(\tilde{\theta}(T, P)) \frac{\partial \tilde{\theta}(T, P)}{\partial C}=p_{C}(\beta-1) f(\tilde{\theta}(T, P))>0 .
$$


(ii) If $T$ is large enough compared to $P$ that (11) is not satisfied, then no one is in favor of $(T, P)$.

Figure 1 below summarizes the partition of the society between those who prefer NH over $\mathrm{HC}$ in the absence of the policy as well as the partition of the society between those who favor the policy and those who do not.

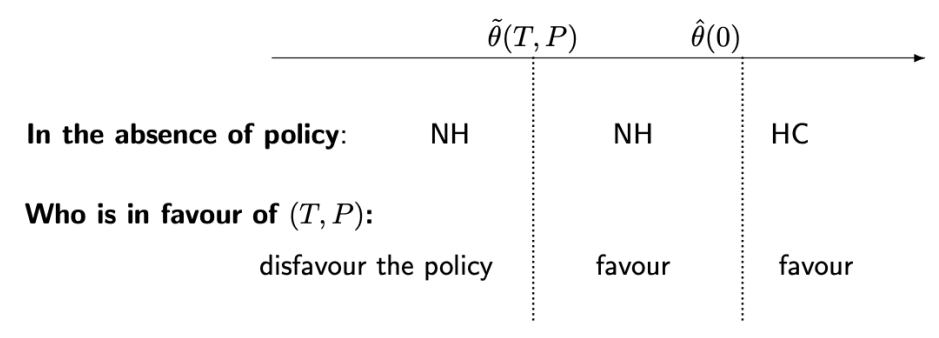

Figure 1: Partition of the population when (11) is satisfied.

Proposition 3 also informs us about how the support for $(T, P)$ (i.e., the set of people in favor of the policy) varies with the risk of a pandemic. We show that $\tilde{\theta}(T, P)$ and $\hat{\theta}(0)$ decrease with $C$, translating into a larger set of agents favoring the policy $(T, P)$.

In this first step of the analysis, we stepped aside from the intensity of the preferences for the policy and focused on how a pandemic risk would affect who will support the policy. In the next subsection, we study the intensity of individuals' preference for the policy.

\subsubsection{Preference intensity}

For a given care preference, $\theta$, the intensity of the preferences for or against the policy could be affected by the pandemic risk. This is what we are interested in in this second step of our analysis.

We define the intensity of the preference for policy $(T, P)$ of an agent with type $\theta$, denoted by $I(\theta, T, P)$, as the difference between the utility levels attained with and without the policy. In each case (i.e., with and without the policy), the agent chooses her optimal care type. We know from above that agents with $\theta<\hat{\theta}(P)$ choose NH while the others choose HC, given the proposed transfer $P$. We also know that $\hat{\theta}$ decreases with $P$, so that $\hat{\theta}(P)<\hat{\theta}(0)$. We then face three types of agents: (i) those with $\theta<\hat{\theta}(P)$ choose NH whether the policy $(T, P)$ is enacted or not, (ii) those with $\theta>\hat{\theta}(0)$ choose $\mathrm{HC}$ in both cases, and (iii) those with $\hat{\theta}(P)<\theta<\hat{\theta}(0)$ prefer $\mathrm{NH}$ in the absence of the transfer, but switch to $\mathrm{HC}$ when the policy $(T, P)$ is enacted.

Agents with $\theta<\hat{\theta}(P)$ remain in $\mathrm{NH}$ with and without the policy, so that their utility 


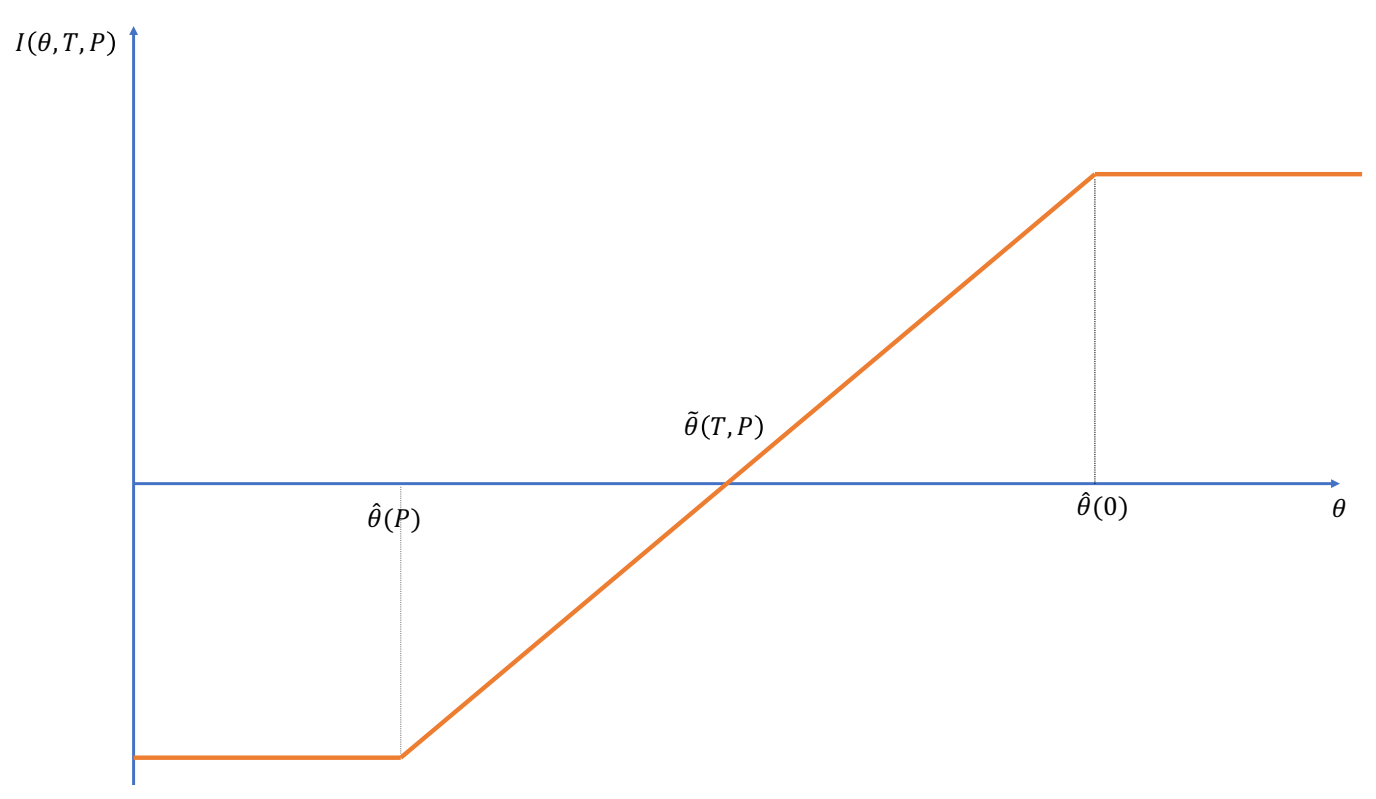

Figure 2: Long-term care preferences, and support for home-care subsidy

differential $I(\theta, T, P)$ is given by:

$$
V_{N H}(\theta, T, P)-V_{N H}(\theta, 0,0)=-T \text {. }
$$

These agents dislike the program (since $\theta<\hat{\theta}(P)<\tilde{\theta}(T, P)$ ) because they pay its tax cost without enjoying its benefit. ${ }^{30}$

Agents with $\theta>\hat{\theta}(0)$ remain in $\mathrm{HC}$ with and without the policy, so that their utility differential $I(\theta, T, P)$ is given by:

$$
\begin{aligned}
V_{H C}(\theta, T, P)-V_{H C}(\theta, 0,0)= & s_{H C}^{*}(0)-s_{H C}^{*}(P)-T \\
& +(1-p)\left[u\left(s_{H C}^{*}(P)\right)-u\left(s_{H C}^{*}(0)\right)\right] \\
& +p\left[u\left(s_{H C}^{*}(P)-L_{H C}+P\right)-u\left(s_{H C}^{*}(0)-L_{H C}\right)\right],
\end{aligned}
$$

whose sign is positive under condition (11).

Finally, the most interesting case consists in studying the change in preferences of agents with $\hat{\theta}(P)<\theta<\hat{\theta}(0)$. For them, the utility differential $I(\theta, T, P)$ is given by:

$$
\begin{aligned}
V_{H C}(\theta, T, P)-V_{N H}(\theta, 0,0)= & \left(s_{N H}^{*}-s_{H C}^{*}(P)\right)-T+(1-p)\left(u\left(s_{H C}^{*}(P)\right)-u\left(s_{N H}^{*}\right)\right) \\
& +p\left[u\left(s_{H C}^{*}(P)-L_{H C}+P\right)-u\left(s_{N H}^{*}-L_{N H}\right)+C p_{C}(\beta-1)+\theta\right],
\end{aligned}
$$

${ }^{30}$ Comparing (8) and (10), we obtain:

$$
\tilde{\theta}(T, P)=\hat{\theta}(P)+\frac{T}{p}>\hat{\theta}(P) .
$$


and is negative if $\theta<\tilde{\theta}(T, P)$ and positive otherwise. Both groups will choose NH in the absence of the policy and $\mathrm{HC}$ under the policy. But the utility gain from switching to $\mathrm{HC}$ is linearly increasing in $\theta$, leaving only those with high enough $\theta$, i.e. $\theta>\tilde{\theta}(T, P)$, being in favor of the policy.

Figure 2 depicts the intensity of the preference for the public policy, $I(\theta, T, P)$, as a function of the agent's type $\theta$.

We now study how this intensity is affected by an increase in NH aversion. This higher $\mathrm{NH}$ aversion can take the form of either an increase in $C, p_{C}$ or $\beta$, or equivalently of an increase in $\theta$. It will prove easier to discuss the second possibility. We then assume that the pandemic risk results in an increase in the value of $\theta$ of each agent by the same amount $\Delta \theta>0$.

Agents with initial $\theta<\hat{\theta}(P)-\Delta \theta$ remain in $\mathrm{NH}$ with and without the policy, even after the pandemic shock, and thus see the intensity of their preferences against the policy unaffected, i.e. $I(\theta, T, P)=-T$ before and after the pandemic. In terms of Figure 2, they remain on the flat part of the curve on the left despite the increase in $\mathrm{NH}$ aversion $\Delta \theta$. Likewise, agents with initial $\theta>\hat{\theta}(0)$ remain in $\mathrm{HC}$ with and without the policy, before and after the pandemic shock. The intensity of their preferences in favor of the policy is then also unaffected by the shock and equal to (13). They remain on the flat portion of the curve on the right.

All other agents see the intensity of their preference for the policy increased following the pandemic shock. In terms of Figure 2, the increase in $\Delta \theta$ moves them to a higher portion of the curve. We can identify three subgroups among those types: (i) agents with $\hat{\theta}(P)<\theta<\hat{\theta}(0)-\Delta \theta$ prefer $\mathrm{NH}$ without the policy and $\mathrm{HC}$ with the policy, before and after the shock, (ii) agents with $\hat{\theta}(P)-\Delta \theta<\theta<\hat{\theta}(P)$ prefer NH without the policy but move to HC with the policy only once the shock occurs, (iii) agents with $\hat{\theta}(0)-\Delta \theta<\theta<\hat{\theta}(0)$ prefer HC even without the policy after the shock.

We will come back to this analysis in a more detailed way in Section 5.3.2.

\section{Data}

The empirical analysis we implement in Section 5 uses data from a survey we conducted as a partnership with AskingCanadians, an online panel survey organization. The survey was fielded to residents of the Canadian provinces of Quebec and Ontario aged 50-69 years, between December $18^{\text {th }}$ and December $31^{\text {st }} 2020$. We constructed survey weights by age, gender, and education using the 2016 Canadian Census to correct for under- and oversampling of certain subgroups, and make it representative of the Ontarian and Quebec population. For questions for which we expected a significant proportion of missing information, such as income, we use unfolding brackets. We then use multiple imputation to assign missing values with information from the bracketing, conditional on basic socio-demographic covariates (age and gender).

Respondents could choose to answer the survey questionnaire in English or French. On 
completion of the survey, respondents received a loyalty reward from their choice of retailer (respondents could choose from a list of major retailers such as Walmart, Petro-Canada, and Hudson's Bay). In total, 3,004 respondents completed the survey.

The questionnaire consists of six main parts: questions about (i) demographics (including age, gender, education, marital status, number of children, health condition), (ii) financial situation (employed or retired, income level, savings amounts and composition, mortgage and property value), (iii) risk perceptions (regarding mortality and needing help with activities of daily living) and (iv) preferences (regarding risk aversion, preference for care from children and, preferences for leaving bequests), (v) a set of strategic survey questions (not used for this paper) and (vi) a set of COVID-related questions. The entire questionnaire can be found in the Appendix A (except for part (v)).

Table 1 summarizes the main socioeconomic and demographic characteristics of our sample once weights are used, and compares these characteristics with those in the 2016 Census and the January 2021 Labour Force Survey for those aged between 50 and 69. Consistent with the construction of our weights, our survey delivers statistics for age, education and gender similar to those in the Census. In terms of marital status, our sample delivers figures broadly in line with those in the Census although it was not used in the construction of the survey weights. In particular, about two thirds of our respondents have a spouse or partner. A little more than half of our sample is employed and about a third is retired. These figures align well with figures from the Labour Force Survey for the same age range although the work status categories do not map perfectly (see table notes). About two-thirds of our respondents have at least one child, and a vast majority of those have at least one child living less than 20 kilometers away. Mean individual income is about $\$ 64,000$. By comparison, according to Statistic Canada, mean income in Ontario in 2019 was respectively $\$ 69,000$ and $\$ 57,000$ for those aged 45 to 54 and those aged 55 to 65 . For Quebec, the figures are $\$ 65,400$ and $\$ 48,600 .{ }^{31}$ Finally, given that our respondents are relatively old and have had time to accumulate wealth, average household (net) wealth (or net worth) in our sample is quite large at about $\$ 765,000$.

\section{$5 \quad$ Empirical results}

Section 3 examined the theoretical implications of nursing home aversion post-pandemic on late-in-life precautionary savings and on the support for a policy subsidizing home care. As shown in Proposition 2, nursing home aversion increases due to a pandemic if the perceived relative exposure to a pandemic in a nursing home compared to home care $(\beta)$ increases, if the overall perceived risk of a pandemic $\left(C\right.$ and $\left.p_{C}\right)$ increases (given $\beta>1$ ), or if individuals update negatively their preferences for nursing home care versus home care (equivalent to an upward shift in the distribution of $\theta$ ) following new (negative) information about nursing homes (e.g.

\footnotetext{
${ }^{31}$ See https://doi.org/10.25318/1110023901-eng
} 
Table 1: Descriptive statistics

\begin{tabular}{lcc}
\hline & Our survey & Census / LFS \\
\hline Québec province (\%) & 39.0 & 38.8 \\
Age (\%) & 28.5 & 28.5 \\
$\quad 50-54$ & 27.6 & 27.6 \\
$55-59$ & 23.4 & 23.4 \\
$60-64$ & 20.5 & 20.5 \\
$\quad 65-69$ & 51.4 & 51.4 \\
Female (\%) & & \\
Marital status (\%) & 51.8 & 59.0 \\
$\quad$ Married & 13.6 & 12.0 \\
Common-law & 18.2 & 18.3 \\
$\quad$ Widowed, separated, divorced & 16.4 & 10.7 \\
$\quad$ Never married & & \\
Education (\%) & 43.2 & 43.2 \\
$\quad$ High school or less & 35.3 & 35.3 \\
College & 21.5 & 21.5 \\
$\quad$ University & 66.8 & - \\
Has a child (\%) & 51.0 & - \\
Has a child < 20km (\%) & & \\
Work status (\%) & 55.0 & 54.4 \\
$\quad$ Employed & 35.3 & 41.1 \\
$\quad$ Retired & 9.6 & 5.2 \\
$\quad$ Not working / Looking for work & 64,028 & - \\
Individual income (average, \$) & 765,205 & - \\
Household wealth (average, \$) & & \\
\hline
\end{tabular}

Notes: The table compares the weighted statistics from our survey to statistics for similar variables in the 2016 Census and in the January 2021 Labour Force Survey (the latter is only used for work status). There is not a perfect mapping between our work status categories and those in the LFS. In the LFS, we classify those "employed at work" or "employed, absent from work" as "employed," those "absent from work / unemployed" as not "not working / looking for work" and the rest (those "not in the labour force") as "retired." 
about the general quality of the care provided). Also as shown in Proposition 2, a higher nursing home aversion should increase the likelihood to save more (as the cost of home care is higher). In addition, as the model predicts that those who plan to use home care would favor a policy which subsidizes it, we expect the additional support for such a policy post-pandemic to stem mainly from those whose nursing home aversion increases, and would now prefer to use HC. ${ }^{32}$

In this section, we provide survey-based empirical evidence for these theoretical predictions. Recall that our sample is aged between 50 and 69 years, so that the questions are not about their immediate use of LTC during the current pandemic but about what they expect to do post-pandemic, as they age. ${ }^{33}$

\subsection{General patterns}

Table 2 summarizes the responses to the key questions related to these predictions (see Appendix A for the questionnaire). First, nursing home aversion post-pandemic is widespread among older Canadians (Panel A). More than $70 \%$ of the respondents reported being less inclined to enter a nursing home. This is not surprising given the media coverage of the COVID-19 outbreaks at nursing homes. To help understand what is behind the change in the inclination, the survey further asks how the respondents' views on nursing homes, in terms of the exposure to health risks, have been affected by the COVID-19 pandemic (Panel B). Again not surprisingly, the current pandemic led them to believe that being in a nursing home will make them more vulnerable to health risks (with almost no difference between private and public nursing homes in that regard). Relating these findings to our theoretical model (see Proposition 2), this is equivalent to considering an increase in $\beta$, if we believe that the health risk respondents had in mind was a higher exposure to a pandemic. Yet, this could also be interpreted as a general upward shift in the $\theta$ distribution if we believe that these responses reflect more a loss of confidence about nursing homes in protecting against general health risks.

Consistent with the theoretical prediction (see Proposition 2), intended savings for older ages increase and the willingness to avoid going to a nursing home seems to be a key driver of these higher intended savings (Panel C). Slightly more than a quarter of the sample $(27 \%)$ reported being willing to save more for older ages because of the pandemic (69\% reported no change, while only $4 \%$ reported being less willing to save due to the pandemic). Among those who indicated a higher willingness to save, the vast majority (83\%) said it is to avoid entering a nursing home.

The attitude towards a policy that subsidizes home care (see Panel D) is also consistent with the theoretical prediction (see Proposition 3). The exact question asked is: "Suppose the government were to propose a policy to increase the access to home care for people needing help with activities of daily living (ADLs) in order to reduce their likelihood of going to a nursing

\footnotetext{
${ }^{32}$ See Proposition 3 and Section 3.4.2.

${ }^{33}$ Our survey excludes any respondent who has already been using LTC services.
} 
Table 2: Intended nursing home use, savings, and preferences for home-care subsidies post-pandemic

\section{A. Intended nursing home use}

More inclined to enter a nursing home

No change

Less inclined to enter a nursing home

$\mathrm{N}$
$2.1 \%$

$26.1 \%$

$71.7 \%$

2,516

\section{B. View on the exposure to health risks at nursing homes}

\section{1) Public nursing homes}

Improved

No change

Worsened

$\mathrm{N}$
$12.9 \%$

$18.3 \%$

$68.9 \%$

2,795

\section{2) Private nursing homes}

Improved

No change

Worsened

$\mathrm{N}$
$11.7 \%$

$17.8 \%$

$70.5 \%$

2,803

\section{Saving for older ages}

1) Changes in willingness to save

Save more

$26.9 \%$

No change

$69.1 \%$

Save less

$4.1 \%$

$\mathrm{N}$

2,755

2) Save more to avoid a nursing home?*

Yes

No

$82.7 \%$

$17.3 \%$

$\mathrm{N}$

\section{View on home-care subsidy}

\section{1) Opinion on the policy}

Very much agree

Agree

Disagree

Very much disagree $\mathrm{N}$
$20.2 \%$

$48.2 \%$

$20.1 \%$

$11.5 \%$

2,504

\section{2) Changes in the opinion}

More in favor

$37.9 \%$

No change

$49.6 \%$

Less in favor

$12.5 \%$

2,294

Note: The number of respondents who completed the survey is 3,004. The tabulation for each question in this table does not include those who chose "Don't know" or "Prefer not to say" as well as those who skipped the question. All the tabulations use the sampling weights.

*This is a follow-up question for those who reported the willingness to save more.

home, but would increase taxes to finance this policy. What do you think would be your opinion about such a policy?" The question thus makes it explicit that such a policy would not be costless and would likely result in higher taxes. Nonetheless, a majority of respondents indicated they would support this policy (20\% very much agreed while another $48 \%$ agreed). Many ( $38 \%$ ) also reported that the pandemic made them more favorable to such a policy (only $13 \%$ reported being less in favor due to the pandemic). 
The unconditional distributions of the survey responses are therefore in line with the predictions from Section 3. Older Canadians become less inclined to use nursing homes, which, in turn, increases their intended savings on the one hand and makes them more favorable to a policy subsidizing home care on the other hand. In the remainder of this section, we present evidence suggesting that the increase in the willingness to save as well as the support for homecare subsidies stem from individuals shying away from nursing homes. We also investigate which socioeconomic characteristics predict nursing home aversion, changes in precautionary savings, and support for home-care subsidies.

Table 3 examines the sample characteristics of the respondents who declared to be less inclined to enter a nursing home due to the pandemic relative to the other respondents. Those who express a higher nursing home aversion (i.e. those who are less inclined to enter a nursing home) post-pandemic are, in comparison with those whose nursing home aversion did not increase, more likely to be Québécois (as opposed to Ontarians), older, females, to live in common-law unions, to hold a university degree and to be retired. On the other hand, we do not find a meaningful difference in whether they have a child or not (also whether they have a child living close), as well as in average income and net worth. Overall, these results show that increased nursing home aversion is not confined to a specific socioeconomic group.

\subsection{Nursing home aversion and savings}

Table $2 \mathrm{C}$ already established that the increase in the willingness to save more is mainly driven by nursing home aversion. We confirm the link between the two by estimating a linear probability model where the dependent variable is the dummy variable of planning to save more due to the pandemic while the key explanatory variable is the dummy variable of being less inclined to enter a nursing home post-pandemic.

As being less inclined to go to a nursing home because of the pandemic might be correlated with demographic or socioeconomic variables such as age or education (see Table 3), we also control for a large set of potential confounding variables. We control for wealth, income, risk aversion, gender, age, province, education, marital status, for whether the respondent has any child, for whether the respondent has any child living close, and for the number of diagnosed health problems and for work status (see Appendix B for further details). ${ }^{34}$

Table 4 shows the estimation results. Results without controls suggest that being less inclined to enter a nursing home increases the chance of being willing to save more by 8.5 percentage points, which is about one-third of the unconditional average reported in Table $2 \mathrm{C}$. Adding controls (Column (2)), the point estimate is even larger, at 10.5 percentage points. Both estimates are statistically significant at the $1 \%$ level. The estimated patterns are similar when the

\footnotetext{
${ }^{34}$ We use imputed values for income although not including respondents for whom income was imputed delivers similar results. Also, we did not include the risk perceptions of respondents (i.e. the probabilities of needing help with ADLs and survival probabilities) as controls, as it significantly reduces the number of observations. Running similar regressions controlling only for these variables delivers comparable point estimates to those reported here.
} 
Table 3: Who are less inclined to enter a nursing home post-pandemic?

\begin{tabular}{|c|c|c|c|}
\hline & $\begin{array}{c}(1) \\
\text { Not less inclined }\end{array}$ & $\begin{array}{c}(2) \\
\text { Less inclined }\end{array}$ & $\begin{array}{c}(3) \\
\text { Difference } \\
(2)-(1)\end{array}$ \\
\hline Québec province (\%) & 33.6 & 39.7 & $+6.1^{* * *}$ \\
\hline \multicolumn{4}{|l|}{ Age $(\%)$} \\
\hline $50-54$ & 31.9 & 26.3 & $-5.5^{* * *}$ \\
\hline $55-59$ & 28.6 & 25.9 & -2.7 \\
\hline $60-64$ & 22.0 & 24.3 & +2.2 \\
\hline $65-69$ & 17.5 & 23.5 & $+6.0^{* * *}$ \\
\hline Female $(\%)$ & 47.6 & 51.7 & $+4.1^{*}$ \\
\hline \multicolumn{4}{|l|}{ Marital status (\%) } \\
\hline Married & 52.8 & 51.6 & -1.2 \\
\hline Common-law & 11.9 & 15.3 & $+3.3^{* *}$ \\
\hline Widowed, separated, divorced & 20.8 & 17.8 & $-3.0^{*}$ \\
\hline Never married & 14.5 & 15.3 & +0.9 \\
\hline \multicolumn{4}{|l|}{ Education (\%) } \\
\hline High school or less & 44.5 & 38.4 & $-6.1^{* * *}$ \\
\hline College & 29.8 & 30.5 & +0.7 \\
\hline University & 25.7 & 31.1 & $+5.4^{* * *}$ \\
\hline Has a child $(\%)$ & 69.1 & 68.6 & -0.5 \\
\hline Has a child $<20 \mathrm{~km}(\%)$ & 53.1 & 51.7 & -1.4 \\
\hline \multicolumn{4}{|l|}{ Work status (\%) } \\
\hline Employed & 61.8 & 51.8 & $-10.0^{* * *}$ \\
\hline Retired & 29.7 & 39.6 & $+9.9^{* * *}$ \\
\hline Not working / Looking for work & 8.5 & 8.6 & +0.1 \\
\hline Individual income (average, $\$$ ) & 67,767 & 65,313 & $-2,454$ \\
\hline Household wealth (average, \$) & 772,824 & 873,181 & 100,357 \\
\hline
\end{tabular}

Note: All the tabulations use the sampling weights. ${ }^{*},{ }^{* *},{ }^{* * *}$ : significant at $10 \%, 5 \%$ and $1 \%$ level respectively.

sample weights are not used (Columns (3) and (4)). If anything, the point estimates are larger. These results confirm that nursing home aversion is one of the main drivers of the increase in the intended saving post-pandemic and that this is not sensitive to controlling for a large set of demographic and socioeconomic variables.

In terms of covariates, we find that that being in Ontario, having a child within 20 kilometers, and being at work predict a higher likelihood to be willing to save more for older ages because of the pandemic (see Table B.1 in the Appendix for details). 
Table 4: Nursing home aversion and saving for older ages

\begin{tabular}{lcccc}
\hline \hline & & & & \\
& $(1)$ & $(2)$ & $(3)$ & $(4)$ \\
\hline Less inclined to enter a nursing home & $.085^{* * *}$ & $.105^{* * *}$ & $.112^{* * *}$ & $.140^{* * *}$ \\
& $(.028)$ & $(.028)$ & $(.019)$ & $(.020)$ \\
\hline$N$ & 2,374 & 2,261 & 2,374 & 2,261 \\
adj. $R^{2}$ & 0.007 & 0.048 & 0.012 & 0.065 \\
\hline Controls & $\mathrm{N}$ & $\mathrm{Y}$ & $\mathrm{N}$ & $\mathrm{Y}$ \\
Use sampling weights & $\mathrm{Y}$ & $\mathrm{Y}$ & $\mathrm{N}$ & $\mathrm{N}$ \\
& & & & \\
\hline \hline
\end{tabular}

Note: This table presents OLS regression results where the dependent variable is whether respondent plans to save more due to the pandemic. Robust standard errors are in parentheses. See the text for the control variables included.

$*, * *, * * *$ : significant at $10 \%, 5 \%$ and $1 \%$ level respectively.

\subsection{Nursing home aversion and home-care subsidy}

\subsubsection{Support for home-care subsidy}

Next, we examine the relationship between the support for a policy that subsidizes home care and increased nursing home aversion. To do so, Figure 3 first plots the percentage of those who "very much disagree," "disagree," "agree," and "very much agree" with the policy, separately for those whose nursing home aversion has increased and the rest. Among those who report to be less inclined to go to a nursing home, $23.8 \%$ report they very much agree with the policy, against $13.2 \%$ of those who declared to be more or equally inclined to go to a nursing home. Hence, this figure suggests that increased nursing home aversion increases the support for home-care subsidy by increasing the probability to "very much agree" with the policy at the expense of the probabilities to "disagree" or simply "agree" with the policy. The most important shift seems to be from the "agree" response to the "very much agree" one.

To confirm this, we present in Table 5 the estimation results from multinomial logit models where the dependent variable is a dummy variable of the support for such a policy in four categories ("very much agree," "agree," "disagree," and "very much disagree"), while the key explanatory variable is being less inclined to enter a nursing home post-pandemic. The same set of control variables as in Table 4 are used. Each column shows the average marginal effects of nursing home aversion in each model. Without any controls (Column (1)), we find, in line with Figure 3, that increased nursing home aversion raises the chances of very much agreeing with subsidizing home care. Indeed, among those respondents who declared to be less inclined to enter a nursing home, their chances to very much agree with the policy is about 12 percentage points higher. This increase in the likelihood to very much agree with the policy is more than half the share of those who very much agree with such a policy (Table 2D). The effect is statistically significant at the $1 \%$ level. The estimated marginal effects are similar if we include 


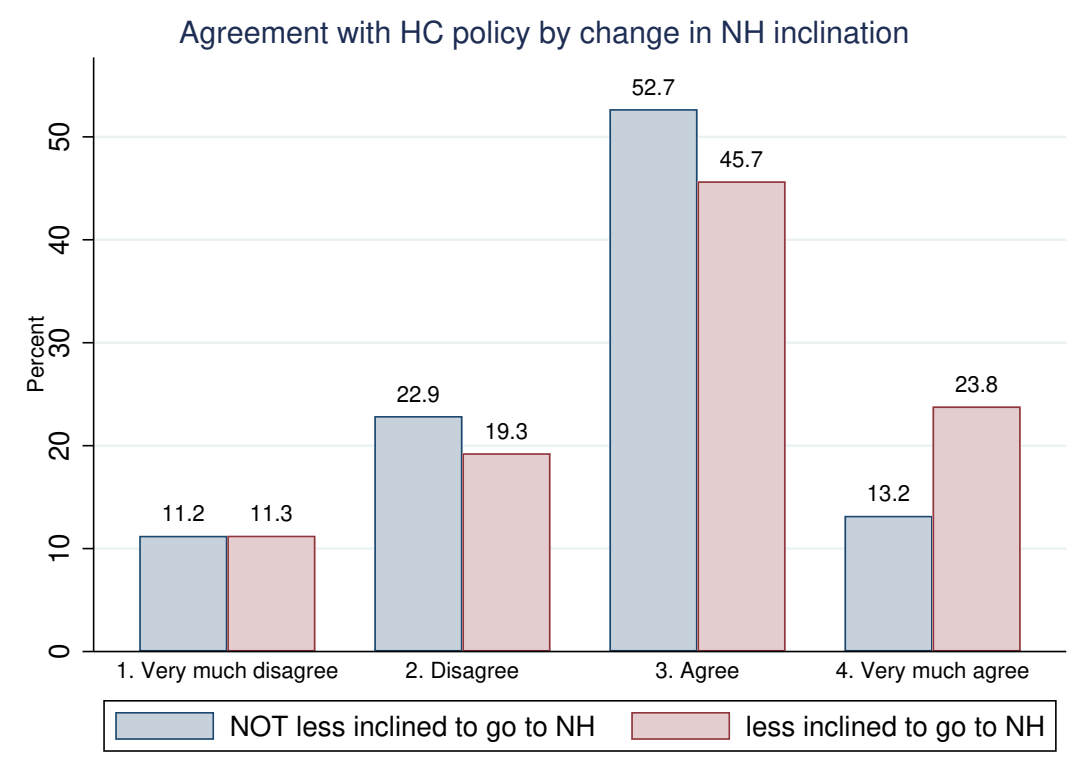

Figure 3: Agreement with home-care subsidy by change in inclination to go to a nursing home Notes: This figure uses sampling weights.

controls (Column (2)). They are also robust to not using sampling weights though the estimated magnitudes are slightly smaller in that case. In line with what we observe in Figure 3, the table confirms that increased nursing home aversion increases the probability to very much agree with the policy at the expense mostly of the probability to simply agree with the policy.

To map these empirical results to our theoretical model and to make sense of the observed patterns, we first reproduce, in Figure 4, the relationship between LTC preferences and the support for home-care subsidy from Figure 2 in Section 3.4.2. Recall that the vertical axis of this figure displays the (net) valuation of the subsidy $P$ (with corresponding taxes $T$ ) as a function of the relative preference for home care $(\theta)$. This valuation, denoted $I(\theta, T, P)$, is the difference between the utility with the subsidy $V(\theta, T, P)$ and without the subsidy $V(\theta, 0,0)$, measured for the chosen type care in each case. Those with $\theta<\hat{\theta}(P)$ choose to go to a nursing home (conditional on needing care) even with the subsidy, and hence, they exhibit the lowest support for this policy. On the other hand, those with $\theta>\hat{\theta}(0)$ would choose home care even without the subsidy, and so they value the subsidy the most. Those with $\theta \in[\hat{\theta}(P), \hat{\theta}(0)]$ will use home care only if the subsidy is implemented. Their support for the policy increases with $\theta$, where the cut-off for being in favour of the policy is $\tilde{\theta}(T, P)$.

We map the level of support for the subsidy in Figure 4 to the four categories of policy support in Table 5 in the following way. The cutoff between "agree" and "disagree" with the policy corresponds to $\tilde{\theta}(T, P)$, with a negative (resp., positive) net benefit from the policy 
Table 5: Support for home-care subsidy and nursing home aversion

\begin{tabular}{|c|c|c|c|c|}
\hline & (1) & $(2)$ & (3) & $(4)$ \\
\hline Very much agree & $\begin{array}{c}.1180^{* * * *} \\
(.0263)\end{array}$ & $\begin{array}{c}.1001^{* * *} \\
(.0271)\end{array}$ & $\begin{array}{c}.0943^{* * *} \\
(.0224)\end{array}$ & $\begin{array}{c}.0732^{* * *} \\
(.0230)\end{array}$ \\
\hline Agree & $\begin{array}{c}-.0769^{* *} \\
(.0308)\end{array}$ & $\begin{array}{c}-.0789^{* * * *} \\
(.0319)\end{array}$ & $\begin{array}{c}-.0663^{* * *} \\
(.0244)\end{array}$ & $\begin{array}{c}-.0673^{* * * *} \\
(.0252)\end{array}$ \\
\hline Disagree & $\begin{array}{l}-.0385 \\
(.0254)\end{array}$ & $\begin{array}{l}-.0334 \\
(.0255)\end{array}$ & $\begin{array}{l}-.0216 \\
(.0183)\end{array}$ & $\begin{array}{l}-.0089 \\
(.0190)\end{array}$ \\
\hline Very much disagree & $\begin{array}{l}-.0022 \\
(.0195)\end{array}$ & $\begin{array}{c}.0123 \\
(.0187)\end{array}$ & $\begin{array}{l}-.0063 \\
(.0149)\end{array}$ & $\begin{array}{l}.0029 \\
(.0154)\end{array}$ \\
\hline$N$ & 2,229 & 2,134 & 2,229 & 2,134 \\
\hline Controls & $\mathrm{N}$ & $\mathrm{Y}$ & $\mathrm{N}$ & $\mathrm{Y}$ \\
\hline Use sampling weights & Y & $\mathrm{Y}$ & $\mathrm{N}$ & $\mathrm{N}$ \\
\hline
\end{tabular}

Note: This table presents the average marginal effects of being less inclined to enter a nursing home on being in each category of support for a policy that subsidizes home care, estimated from multinomial logit regressions. Robust standard errors are in parentheses. See the text for the control variables included. $*, * *, * * *$ : significant at $10 \%, 5 \%$ and $1 \%$ level respectively.

below (resp., above). There is some arbitrariness in the thresholds used to separate "very much disagree" from "disagree" $(\underline{I})$ and "very much agree" from "agree" $(\bar{I})$, and we assume that the former is above the minimum level of support (i.e. the level of support arising from those with $\theta<\hat{\theta}(P))$ while the latter is below the maximum level of support (i.e. that from those with $\theta>\hat{\theta}(0))$, as depicted in Figure 4. The corresponding thresholds in terms of preferences are denoted $\theta_{\underline{I}}$ and $\theta_{\bar{I}} \cdot 35$

We model the nursing home aversion caused by the pandemic in the following way. The distribution of $\theta$ before the pandemic is denoted by $F(\theta)$. During the pandemic, a random subset of the population learn negative information about nursing homes and hence, their relative preference for home care increases by $\Delta \theta>0$. These agents form the 'less-inclined' group from Figure 3. As a result, the preference distribution of the less-inclined group is a parallel rightward shift of that of the complementary group (i.e. the 'not less inclined' group in Figure 3).

Under this assumption, the distribution of the policy support within the group with no change in LTC preferences (i.e. the blue bars in Figure 3) reveals the underlying distribution $F(\theta)$ prepandemic. A majority (52.7\%) belong to the "agree" category (i.e., those with $\left.\theta \in\left(\tilde{\theta}(T, P), \theta_{\bar{I}}\right)\right)$. They would have used home care only with the subsidy and would have obtained positive net

\footnotetext{
${ }^{35}$ These thresholds may vary across respondents, but this does not affect our analysis of the impact of nursing home aversion on the overall change in the support for subsidizing home care.
} 


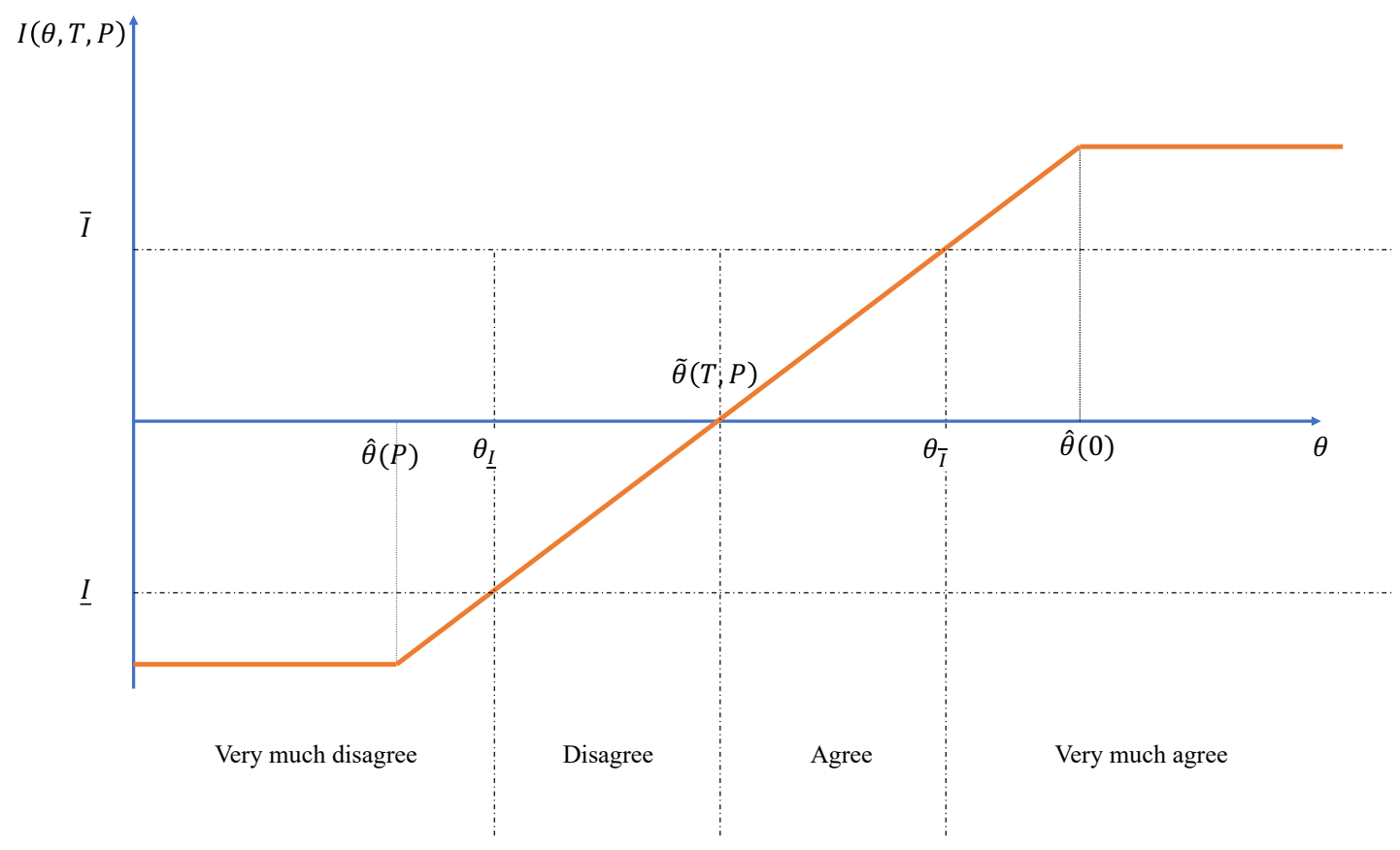

Figure 4: Long-term care preferences and mapping to the categories of the support for $\mathrm{HC}$ subsidy

utility from such a subsidy. About one-fifth (22.9\%) would have used home care with the subsidy though they would have preferred not having such a policy. For a small fraction of the population, the subsidy would have had no effect on their choice, putting them in either of the two extreme categories in terms of the policy support.

Regarding the impact of the nursing home aversion on the policy support, the model predicts that the less-inclined group should have a stronger support for the policy compared to the complementary group. In particular, the chance that those who belong to the less-inclined group would "very much agree" with the policy should increase (by $\int_{\theta_{\bar{I}}-\Delta \theta}^{\theta_{\bar{I}}} d F(\theta)$ ), while the chance that they would "very much disagree" with the policy should decrease (by $\int_{\theta_{\underline{I}}-\Delta \theta}^{\theta_{I}} d F(\theta)$ ). As a result, for the middle two categories, the expected change in the proportions of people belonging to these categories is ambiguous as there is an outflow to the category on the right as well as an inflow from the category on the left. A large and positive marginal effect of nursing home aversion on the chance of "very much agreeing" with the policy in Table 5 indeed support the prediction from the model. We do not find statistically significant evidence that nursing home aversion reduces the chance of "very much disagreeing" with the policy, but only a very small fraction of the population belonged to this category of the policy support to begin with (Figure 3). Lastly, a significant and negative marginal effect on the "agree" category suggests that the outflow from this category to the "strongly agree" category is much larger than the inflow from 
the "disagree" to the "agree" category (i.e. $\left.\int_{\tilde{\theta}(T, P)-\Delta \theta}^{\tilde{\theta}(T, P)} d F(\theta)<\int_{\theta_{\bar{T}}-\Delta \theta}^{\theta_{\bar{T}}} d F(\theta)\right)$. This is consistent with the fact that there were much fewer people "disagreeing" with the policy compared to those who "agreed" with the policy pre-pandemic (Figure 3). So overall, the empirical results on the impact of nursing home aversion on the policy support are consistent with the key prediction from the model.

Note that the above interpretation relies on the assumption that the less-inclined group is drawn randomly from the pre-pandemic distribution of $\theta$, which also implies no correlation between the chance of having a shift in the preference $(\Delta \theta)$ and the pre-pandemic preference $(\theta)$. Since our regressions control for many demographic and socio-economic variables, the identified effects are free from potential correlation between the pre-pandemic preference and the impact of the pandemic that can be explained by those controls. In the next subsection, we look at the self-declared change in support for the policy because of the pandemic which de facto tackles concerns about unobserved heterogeneity.

Marginal effects of the controls entering columns 2 and 4 of Table 5 are reported in Tables B.2 and B.3 in the Appendix. We find that those in the top three wealth quartiles are more in favor of the policy (compared to those in the bottom wealth quartile) but that being in the top income quartile reduces the support for the policy (compared to those in the bottom income quartile). We also find that Québécois, those with at least a high school diploma, those who are currently working, those with more health problems, and those divorced or separated tend to be more in favor of such a policy.

\subsubsection{Change in support for home-care subsidy}

We saw that increased nursing home aversion is associated with more support for a policy subsidizing home care. However, the previous estimates might not reflect any causal effect of increased nursing home aversion on the support for such a policy, as increased nursing home aversion and pre-pandemic support for the policy might be positively associated.

However, our survey also asked respondents how their support for such a policy changed because of the pandemic, and we confirm that increased nursing home aversion is also associated with increased support for a home-care subsidy after the COVID pandemic, which provides support for our interpretation in Section 5.3.1. To show this, Figure 5 first plots the change in the agreement with the policy separately for those less inclined to go to a nursing home because of the pandemic and for the rest. This figure suggests that increased nursing home aversion is associated with a much higher probability to be more in favor of the policy after the pandemic.

In Table 6, we further report the results from a multinominal logit estimation where the setup is identical to that in Table 5 except that the dependent variable is a dummy of the categories on the change in the support ("less in favor," "more in favor," and "no change") for home-care subsidy due to the pandemic. In line with Figure 5, being less inclined to use a nursing home increases the chance of being more in favor of the policy by about 25 percentage points, which 


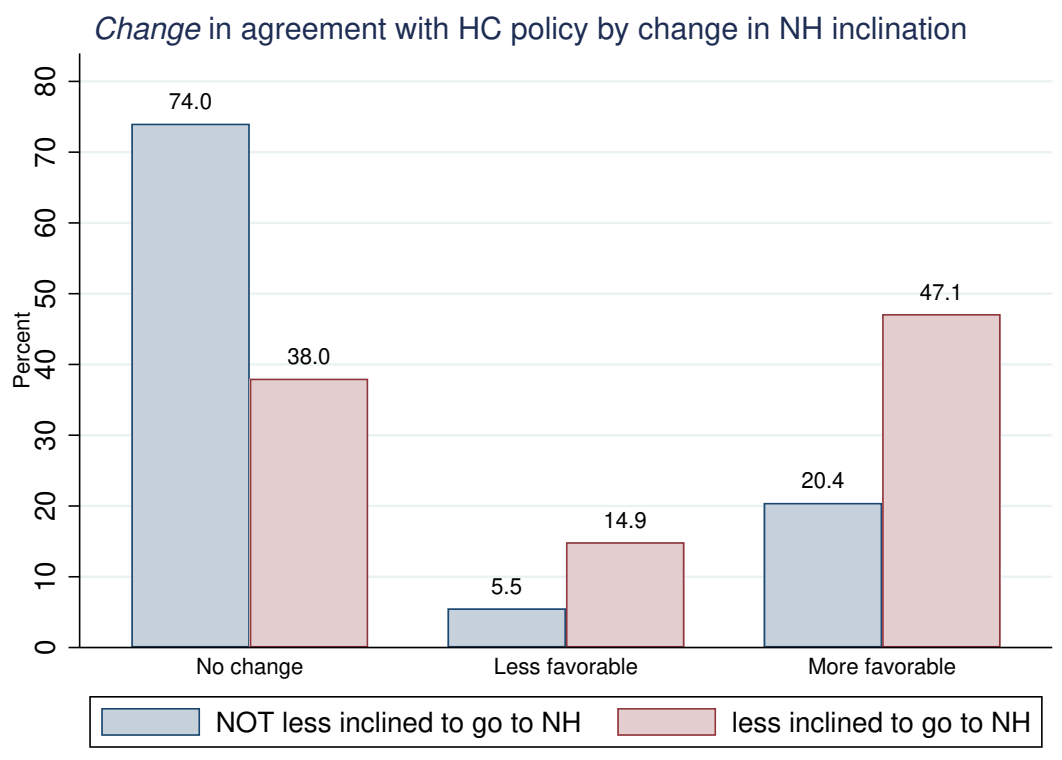

Figure 5: Change in agreement with home-care subsidy by change in inclination to go to a nursing home

Notes: This figure uses sampling weights.

is robust to including controls and not using sampling weights. This is a large change, given that it represents about two-thirds of the fraction of those who became more in favor of such a policy (i.e. $38 \%$, see Table 2D).

Our model, summarized in Figure 4, predicts that the less-inclined group, whose relative preference for home care increased by $\Delta \theta>0$, should be more in favor of a home-care subsidy (unless they already had a highest level of support, i.e. $\theta>\hat{\theta}(0)$ ). On the other hand, the complementary group, whose preference (equivalently, the degree of nursing home aversion) was not affected by the pandemic, should exhibit no change in the support for the policy. Hence, the estimation results - nursing home aversion increasing the chance of being more in favor of the policy while decreasing the chance of having no change in the support - are in line with the predictions from the model. ${ }^{36}$

Marginal effects of the control variables entering Columns (2) and (4) of Table 6 are reported in Tables B.4 and B.5 in the Appendix. We find that those in the top three wealth quartiles have

\footnotetext{
${ }^{36}$ The less-inclined group is also associated with a higher chance of being less in favor of the policy (around 9 percentage points) though this relationship is much smaller than what we see for the other categories. One possible explanation is that this pattern is driven by individuals who are generally skeptical about the ability of governments to deliver appropriate public LTC policies, a feature we do not model. Some evidence seems globally in line with this explanation, although only suggestive. For instance, among those who became less in favor of the policy and also became less inclined to go to a nursing home after the pandemic, $73 \%$ either disagree or very much disagree with the policy while for the rest of the sample, this figure is only $28 \%$.
} 
Table 6: Change in the support for home-care subsidy and nursing home aversion

\begin{tabular}{lcccc}
\hline \hline & & & & \\
& $(1)$ & $(2)$ & $(3)$ & $(4)$ \\
\hline No change & $-.3441^{* * *}$ & $-.3369^{* * *}$ & $-.3449^{* * *}$ & $-.3540^{* * *}$ \\
& $(.0256)$ & $(.0269)$ & $(.0208)$ & $(.0219)$ \\
Less in favor & $.0949^{* * *}$ & $.0994^{* * *}$ & $.0807^{* * *}$ & $.0938^{* * *}$ \\
& $(.0282)$ & $(.0273)$ & $(.0200)$ & $(.0206)$ \\
More in favor & $.2492^{* * *}$ & $.2374^{* * *}$ & $.2642^{* * *}$ & $.2602^{* * *}$ \\
& $(.0315)$ & $(.0321)$ & $(.0251)$ & $(.0261)$ \\
\hline \hline$N$ & 2,081 & 2,002 & 2,081 & 2,002 \\
\hline Controls & $\mathrm{N}$ & $\mathrm{Y}$ & $\mathrm{N}$ & $\mathrm{Y}$ \\
Use sampling weights & $\mathrm{Y}$ & $\mathrm{Y}$ & $\mathrm{N}$ & $\mathrm{N}$ \\
& & & & \\
\hline \hline
\end{tabular}

Note: This table presents the average marginal effects of being less inclined to enter a nursing home on being in each category of change in the support for a policy that subsidizes home care, estimated from multinomial logit regressions. Robust standard errors are in parentheses. See the text for the control variables included.

$*, * *, * * *$ : significant at $10 \%, 5 \%$ and $1 \%$ level respectively.

a higher probability to declare themselves more in favor of the policy because of the pandemic (compared to those in the bottom wealth quartile), but that being in the top income quartile reduces this probability (compared to being in the bottom income quartile). Being from Quebec increases the probability to declare no change in support for the policy, mainly at the expense of being less in favor of the policy. Educational attainment higher than or equal to completing high school is associated with a higher probability to be more in favor of the policy. Finally, being widowed or divorced (compared to being married) and currently not working reduce the probability to be less in favor of the policy.

To sum up this section, survey evidence reveals that the information older individuals obtained about nursing homes during the pandemic affected their expected choice of LTC, making them less inclined to enter a nursing home. The individuals that become more averse to entering a nursing home plan to save more in order to cover the higher cost needed to have proper LTC at home. At the same time, those individuals also expressed strong support for a policy that subsidizes home care, which could partially substitute for costly precautionary savings. Our theoretical framework provides a coherent explanation to all these observations about LTC-related choices post-pandemic. 


\section{Conclusion}

The current COVID pandemic will change many aspects of our life post-pandemic. Its impact on LTC can be particularly large and persistent, due to COVID outbreaks at nursing homes during the first wave of the pandemic and negative information about nursing homes people obtained through the media coverage of these outbreaks. Many people will choose to avoid entering a nursing home and instead receive LTC at home, notwithstanding the higher cost of the latter. Our model of LTC choice shows that such nursing home aversion will increase households' desired savings for old ages. The model also shows that, since such self-insurance is costly, households will support a policy that will make home care more affordable. The evidence from our survey supports all these predictions from our model. Overall, the results of this paper show the importance of designing appropriate policies that would provide affordable alternatives to nursing home care for the elderly population, and that these may find strong support in the population.

\section{References}

[1] Achou, B., 2020, Housing in Medicaid: Should it Really Change?, Retirement and Savings Institute Working Paper, No. 3.

[2] Antràs, P., Redding, S., and Rossi-Hansberg, E., 2020, Globalization and Pandemics, NBER Working Paper, 27840.

[3] Ameriks, J., Caplin, A., Laufer, S., and Van Nieuwerburgh, S., 2011, The Joy of Giving or Assisted Living? Using Strategic Surveys to Separate Public Care Aversion from Bequest Motives, Journal of Finance, 66, 519-561.

[4] Ameriks J., J. S. Briggs, A. Caplin, M. D. Shapiro, and C. Tonetti, 2020, Long-term-care Insurance Puzzle: Modeling and Measurement, Journal of Political Economy, 128, 23752451.

[5] Barsky, R., F. Juster, M. Kimball, and M. D. Shapiro, 1997, Preference Parameters and Behavioral Heterogeneity: an Experimental Approach in the Health and Retirement Studies, Quarterly Journal of Economics, 112, 537-579.

[6] Bonadio, B., Z. Huo, A. Levchenko, and N. Pandalai-Nayar, 2021, Global Supply Chains in the Pandemic, NBER Working Paper, 27224.

[7] Boyer, M.M., P. De Donder, C. Fluet, M-L. Leroux, and P-C. Michaud, 2020, Long-term Care Insurance: Information Frictions and Selection, American Economic Journal: Economic Policy, 12, 134-69. 
[8] Braun, R.A., K. Kopecky, and T. Koreshkova, 2017, Old, Sick, Alone, and Poor: a Welfare Analysis of Old-Age Social Insurance, Review of Economic Studies, 84, 580-612.

[9] Brown, J. R. and A. Finkelstein, 2009, The Private Market for Long-Term Care Insurance in the United States: A Review of the Evidence, Journal of Risk and Insurance, 76, 5-29.

[10] Bricongne, J-C., J. Carluccio, L. Fontagné, G. Gaulier, and S. Stumpner, 2021, The Margins of Adjustment of French Exports to the COVID Crisis, Working Paper, available at: https : //www.dropbox.com/s/awu7eumkfv9vmps/BCFGS.pdf?dl=0

[11] Canadian Institute for Health Information, 2020, Pandemic Experience in the LongTerm Care Sector: How Does Canada Compare with Other Countries? Ottawa, ON: CIHI. Available at: https://www.cihi.ca/sites/default/files/document/ covid-19-rapid-response-long-term-care-snapshot-en.pdf

[12] Cajner T., D.C. Crane, R.A. Decker, J. Grigsby, A. Hamins-Puertolas, E. Hurst, C. Kurz, and A. Yildirmaz, 2020, The U.S. Labor Market during the Beginning of the Pandemic Recession, NBER Working Paper, 27159.

[13] Canta C., P. Pestieau, and E. Thibault, 2016, Long-term Care and Capital Accumulation: the Impact of the State, the Market and the Family, Economic Theory, 61, 755-785.

[14] Clavet N-J., Y. Décarie, R. Hébert, P-C. Michaud and J. Navaux, 2021, Le Financement du Soutien à l'Autonomie des Personnes Âgées à la Croisée des Chemins, CREEI Working paper, 21-01.

[15] Commissaire à la Santé et au Bien-être, 2017, Les Personnes de 75 ans et plus en Attente d'une Place d'Hébergement en CHSLD, Bulletin numéro 16.

[16] Courbage C. and L. Eeckhoudt, 2012, On Insuring and Caring for Parents' Long-term Care Needs, Journal of Health Economics, 31, 842-850.

[17] Courbage C. and G. Montoliu-Montes, 2018, Estate Fiscal Policies, Long-term Care Insurance and Informal Care, working paper, https://hesso.tind.io/record/2651? In=fr

[18] Cremer H. and P. Pestieau, 2014, Social Long-term Care Insurance and Redistribution, International Tax and Public Finance, 21, 955-974.

[19] De Donder P., and M-L. Leroux, 2013, Behavioral Biases and Long Term Care Annuities: A Political Economy Approach, The B.E. Journal of Economic Analysis \& Policy (Advances), $14(2)$.

[20] De Donder P. and P. Pestieau, 2017, Private, Social, and Self-insurance for Long-term Care in the Presence of Family Help, Journal of Public Economic Theory, 19, 18-37. 
[21] De Nardi, M., E. French, and J.B. Jones, 2010, Why Do the Elderly Save? The Role of Medical Expenses, Journal of Political Economy, 118, 39-75.

[22] De Nardi, M., E. French, and J.B. Jones, 2016, Medicaid Insurance in Old Age, American Economic Review, 106, 3480-3520.

[23] Gollier C., 2020, Cost-benefit Analysis of Age-specific Deconfinement Strategies, Journal of Public Economic Theory, 22, 1746-1771.

[24] Hurwitz A., O.S. Mitchell, and O. Sade, 2021, Longevity Perceptions and Saving Decisions during the COVID-19 Outbreak: An Experimental Investigation, American Economic Review: Papers and Proceedings, 111, 297-301.

[25] Kahn, L. B., F. Lange, and D. G. Wiczer, 2020, Labor Demand in the Time of Covid-19: Evidence from Vacancy Postings and UI claims, Journal of Public Economics, 189, 104-238.

[26] Klimaviciute, J. and P. Pestieau, 2018, Long-term Care Social Insurance: How to Avoid Big Losses?, International Tax and Public Finance, 25, 99-139.

[27] Kopczuk, W. and Lupton, J. P., 2007, To Leave or not to Leave: the Distribution of Bequest Motives, The Review of Economic Studies, 74, 207-235.

[28] Kopecky, K. A. and T. Koreshkova, 2014, The Impact of Medical and Nursing Home Expenses on Savings and Inequality, American Economic Journal: Macroeconomics, 6, 29-72.

[29] Koreshkova, T. and M. Lee, 2020, Nursing Homes in Equilibrium: Implications for Longterm Care Policies, University of Michigan Retirement and Disability Research Center Working Paper, WP 2020-414.

[30] Kurmann A., E. Lalé, and L. Ta, 2021, The Impact of COVID-19 on Small Business Dynamics and Employment: Real-time Estimates With Homebase Data, Working Paper available at http://conference.iza.org/conference_files/Statistic_2021/10234.pdf

[31] Leroux M-L. and P. Pestieau, 2020, Age-related Taxation of Bequests in the Presence of a Dependency risk, Journal of Public Economic Theory, forthcoming, https://doi.org/10. 1111/jpet. 12539

[32] Lockwood, L. M., 2018, Incidental Bequests: Bequest Motives and the Choice to Self-Insure Late-Life Risks, American Economic Review, 108, 2513-2550.

[33] National Institute on Ageing, 2021, Pandemic Perspectives on Long-Term Care: Insights from Canadians in Light of COVID-19, available at https://www.cma.ca/sites/default/ files/pdf/Activities/National-Institute-on-Ageing-CMA-Report-EN.pdf 
[34] OECD, 2011, Help Wanted? Providing and Paying for Long-Term Care, available at https: //www.oecd.org/els/health-systems/help-wanted-9789264097759-en.htm

[35] Palumbo, M. G., 1999, Uncertain Medical Expenses and Precautionary Saving Near the End of the Life Cycle, The Review of Economic Studies, 66, 395-421.

[36] Pestieau, P. and G. Ponthiere, 2011, The Long Term Care Insurance Puzzle, in J. CostaFont and C. Courbage (eds.): Financing Long Term Care in Europe: Institutions, Markets and Models, Palgrave Macmillan, London, 41-52.

[37] Revenu Québec, 2019, Les Grandes Lignes du Crédit d'Impôt pour Maintien à Domicile des Aînés, ISBN 978-2-550-85475-3.

[38] Salanié F. and N. Treich, 2020, Public and Private Incentives for Self-Protection, The Geneva Risk and Insurance Review, 45, 104-113.

[39] Tousignant, M., N. Dubuc, R. Hébert, and C. Coulombe, 2007, Home-care Programmes for Older Adults with Disabilities in Canada: How can We Assess the Adequacy of Services Provided compared with the Needs of Users? Health \& Social Care in the Community, 15, $1-7$. 


\section{A Appendix: Survey questionnaire}

\section{Section 1: Background}

QA Which of the following best describes your gender?

1 Male

2 Female

QB How old are you? Please Enter. [PN: MUST ENTER THE 2 CHARACTERS.] [RANGE 50-69] Numeric

[PN: TERMINATE IF NOT 50-69 INCLUSIVELY]

QC Which province or territory do you live in?

1. British Columbia

2. Alberta

3. Saskatchewan

4. Manitoba

5. Ontario

6. Quebec

7. New Brunswick

8. Nova Scotia

9. Prince Edward Island

10. Newfoundland and Labrador

11. Northwest Territories

12. Nunavut

13. Yukon

14. None of the above

[PN: TERMINATE IF QC IS NOT 5 or 6 ]

[PN:

DEFINE NH_LONG = « long-term care home $(C H S L D)$ » IF QC==6;

DEFINE NH_LONG = «long-term care home» IF QC==5;

DEFINE NH_SHORT $=$ «CHSLD »IF QC==6;

DEFINE NH_SHORT $=$ «long-term care home $» I F Q C==5$

DEFINE NH_SHORT2 = «long-term care homes» IF QC==6;

DEFINE NH_SHORT2 $=$ « long-term care homes» IF QC==5

]

QD Do you need help with any activities of daily living, that is help with activities such as bathing, dressing, eating, walking across a room, and getting in or out of bed?

1 Yes

2 No 
[PN: TERMINATE IF QD IS 1]

Q1 What is the highest degree, certificate or diploma you have obtained?

1 Less than high school diploma or its equivalent

2 High school diploma or a high school equivalency certificate

3 Trade certificate or diploma

4 College, CEGEP or other non-university certificate or diploma (other than trade certificates or diplomas)

5 University certificate or diploma below the bachelor's level

6 Bachelor's degree (e.g. B.A., B.Sc., LL.B.)

7 University certificate, diploma, degree above the bachelor's level

Q2 What is your marital status?

1 married

2 living common-law

3 widowed

4 separated

5 divorced

6 single, never married

Q2a [PN: ASK IF Q2==1 or 2] How old is your partner (spouse)? [RANGE 18 - 100]

Q3 Do you have any children?

1 Yes

2 No

Q3a [PN: ASK IF Q3==1] How many children do you have who live less than $20 \mathrm{~km}$ away from your main residence? [RANGE 0 - 20]

Q4 At the present time, do you smoke cigarettes daily, occasionally or not at all?

1 Daily

2 Occasionally

3 Not at all

[PN: ASK IF Q4==2 or 3][SHOW ON SAME PAGE AS Q4]

Q4a Have you ever smoked cigarettes daily?

1 Yes

2 No

Q5 Looking at the following list of health conditions, has a doctor ever told you that you had:

[PN: MULTIPLE SELECT]

1 Heart disease 
2 Stroke

3 Lung disease

4 Diabetes

5 Hypertension

6 Depression or other mental health problems

7 Cancer 


\section{Section 2: Financial situation}

[PN: THE VARIABLES “RETIRED”, "INCOME” AND “WEALTH” ARE DEFINED THROUGH THIS SERIES OF QUESTIONS AND WILL BE USED IN THE EXPERIMENT IN SECTION 6.]

Q6 Which of the following statements best describes your current work situation? Note that by being "retired", we mean that you have stopped working entirely.

1 Employed (full time, part time, seasonal work)

2 Retired

3 Looking for work

4 Not working, but for reasons other than retired

8888888 Prefer not to say

[PN: DEFINE RETIRED=1 IF Q6==2. DEFINE RETIRED=0 OTHERWISE.]

Q7

For 2019, what is your best estimate of your total income, before taxes and deductions? Please include all sources of income, such as salaries and wages, tips, gross self-employment income and fees, parental benefits, income received from sole-owner small businesses, pensions, investment income, workers' compensation benefits, social benefits, and gross rental income. If you did not have any income in 2019, please enter 0 (zero).

[PN: PROVIDE BOX FOR NUMERICAL ANSWER] [RANGE: 0 - 2000000 \$]

Numeric

9999999 Don't know or prefer not to say

[PN: ASK IF Q7==9999999 (ON SAME SCREEN)]

Q7a Is it more than $\$ 60,000$ ? 1 Yes 2 No 7777777 Don't know 8888888 Prefer not to say

[PN: IF Q7a==7777777 OR 8888888, TYPE_INCOME==12]

[PN: ASK IF Q7a==1 (ON SAME SCREEN)]

Q7b Is it less than $\$ 80,000$ ? 1 Yes 2 No 7777777 Don't know 8888888 Prefer not to say

[PN: IF $Q 7 b==1$, TYPE_INCOME $==2$

IF Q7b==7777777 OR 8888888, TYPE_INCOME==3]

[PN: ASK IF Q7b==2 (ON SAME SCREEN)]

Q7c Is it more than $\$ 100,000$ ? 1 Yes 2 No 7777777 Don't know 8888888 Prefer not to say

[PN: IF Q7c==1, TYPE_INCOME $==4$

IF Q7c $==2$, TYPE_INCOME $==5$

IF Q7c==7777777 OR 8888888, TYPE_INCOME==6]

[PN: ASK IF Q7a==2 (ON SAME SCREEN)]

Q7d Is it more than $\$ 40,000$ ? 1 Yes 2 No 7777777 Don't know 8888888 Prefer not to say

[PN: IF Q7d==1, TYPE_INCOME $==7$

IF Q7d==7777777 OR 8888888, TYPE_INCOME==8] 
[PN: ASK IF Q7d==2 (ON SAME SCREEN)]

Q7e Is it more than $\$ 20,000$ ? 1 Yes 2 No 7777777 Don't know 8888888 Prefer not to say [PN: IF Q7e==1, TYPE_INCOME $==9$

IF Q7e $==2$, TYPE_INCOME $==10$

IF Q7e==7777777 OR 8888888, TYPE_INCOME==11]

[PN: CREATE VARIABLE "INCOME" AND DEFINE IT IN THE FOLLOWING WAY:

\begin{tabular}{|l|l|}
\hline TYPE_INCOME & INCOME \\
\hline 1 & Q7 \\
\hline 2 & 70,000 \\
\hline 3 & 80,000 \\
\hline 4 & 130,000 \\
\hline 5 & 90,000 \\
\hline 6 & 100,000 \\
\hline 7 & 50,000 \\
\hline 8 & 40,000 \\
\hline 9 & 30,000 \\
\hline 10 & 10,000 \\
\hline 11 & 20,000 \\
\hline 12 & 60,000 \\
\hline
\end{tabular}

[PN: DEFINE WEALTH = 0 BEFORE THIS QUESTION.]

Q8 For each of these saving accounts, please indicate the approximate market value held by [IF Q2==1,2, DISPLAY "you and your partner (spouse)", ELSE DISPLAY "yourself"], if any, as of today. If you do not have a certain type of account, please enter 0 (zero) for that account.

\begin{tabular}{|c|c|}
\hline Account type & $\begin{array}{l}\text { A. Market value held by } \\
\text { household (in \$) }\end{array}$ \\
\hline $\begin{array}{l}\text { 1 RRSP (Registered Retirement } \\
\text { Savings Plan), both individual and } \\
\text { group-based }\end{array}$ & $\begin{array}{l}\text { [FORMAT } \$ 99,999,999- \\
\text { RANGE \$0- } \$ 99,999,999]\end{array}$ \\
\hline $\begin{array}{l}2 \text { TFSA (Tax Free Savings } \\
\text { Account), both individual and } \\
\text { group-based }\end{array}$ & $\begin{array}{c}\text { [FORMAT } \$ 99,999,999 \\
\text { RANGE \$0- } \$ 99,999,999]\end{array}$ \\
\hline $\begin{array}{l}\text { 3 Other registered savings plans } \\
\text { (for instance, RESP, RDSP, LIRA, } \\
\text { RRIF, LIF) [PN: Mouse-over } \\
\text { definitions: Registered Education } \\
\text { Savings Plan (RESP), Registered } \\
\text { Disability Savings Plan (RDSP), } \\
\text { Locked-In Retirement Account } \\
\text { (LIRA), Registered Retirement }\end{array}$ & $\begin{array}{c}\text { [FORMAT } \$ 99,999,999 \\
\text { RANGE \$0- } \$ 99,999,999]\end{array}$ \\
\hline
\end{tabular}




\begin{tabular}{|l|c|}
\hline $\begin{array}{l}\text { Income Fund (RRIF), Life Income } \\
\text { Funds (LIF)] }\end{array}$ \\
\hline $\begin{array}{l}\text { 4 Other savings / investments } \\
\text { not included above (cash, bank } \\
\text { accounts, investment accounts } \\
\text { that are not registered, etc.) }\end{array}$ \\
\hline
\end{tabular}

[PN: WEALTH $=$ Q8_1+Q8_2+Q8_3+Q8_4.]

Q9 Do you [IF Q2==1,2, DISPLAY "or your partner (spouse)"] own any of the real estate properties listed below? Please select all that apply.

[PN: MULTI-SELECT, FOR 1 AND 2 ONLY]

1 Primary residence

2 Secondary residence or other residential real estate

9999999 Do not own any residences or other real estate

[PN: ASK IF Q9==1 or 2]

Q9a Please indicate in the table below your best estimate of the total combined market value and mortgage balance outstanding of all your real estate properties.

\begin{tabular}{|l|l|}
\hline $\begin{array}{l}\text { A. Total real estate } \\
\text { market value }\end{array}$ & $\begin{array}{l}\text { B. Total of mortgage } \\
\text { balances outstanding }\end{array}$ \\
\hline [FORMAT: \$99,999,999- & [FORMAT: \$99,999,999- \\
RANGE \$0 TO & RANGE \$0 TO 2*[value in \\
column A] ] $999,999]$. & \\
& \\
\hline
\end{tabular}




\section{Section 3: Risk Perception}

Next we would like to ask your opinion about how likely you think various events might be. When we ask a question, we'd like you to give us a number from 0 to 100 , where "0" means that you think there is absolutely no chance, and "100" means that you think the event is absolutely certain to happen. For example, no one can ever be sure about tomorrow's weather, but if you think that rain is very unlikely tomorrow, you might say that there is a 10 percent chance of rain. If you think there is a very good chance that it will rain tomorrow, you might say that there is an 80 percent chance of rain.

\section{[PN: SHOW Q10-Q12 ON THE SAME SCREEN]}

\section{[PN: ASK IF QB<=65]}

Q10 What do you think is the likelihood you will live to age $\mathbf{7 0}$ ? Please enter a number between 0 and 100, 0 meaning you expect there is no chance you will live to 70, and 100 meaning that you will live to 70 with certainty.

[PN: PROVIDE BOX FOR NUMERICAL ANSWER] [RANGE: 0 - 100]

Numeric

7777777 Don't know

8888888 Prefer not to say

\section{[PN: ASK IF QB>65 OR (Q10>0 AND IS NUMERIC) ]}

Q11 What do you think is the likelihood you will live to age $\mathbf{8 0}$ ? Please enter a number between 0 and 100, 0 meaning you expect there is no chance you will live to 80 , and 100 meaning that you will live to 80 with certainty.

[PN: PROVIDE BOX FOR NUMERICAL ANSWER] [RANGE: 0 - [RESPONSE TO Q10]] Numeric

7777777 Don't know

8888888 Prefer not to say

[PN: Ask if Q11>0 and is Numeric]

Q12 What do you think is the likelihood you will live to age $\mathbf{9 0}$ ? Please enter a number between 0 and 100, 0 meaning you expect there is no chance you will live to 90, and 100 meaning that you will live to 90 with certainty.

[PN: PROVIDE BOX FOR NUMERICAL ANSWER] [RANGE: 0 - [RESPONSE TO Q11]] Numeric

7777777 Don't know

8888888 Prefer not to say

[PN: SHOW Q13 - Q14 ON THE SAME SCREEN]

Q13 What do you think is the likelihood that you will need help with any activities of daily living, that is activities such as bathing, dressing, eating, walking across a room, and getting in or out of bed, for at least one year before you die? [PN: PROVIDE BOX FOR NUMERICAL ANSWER] [RANGE: 0 - 100] 
Numeric

7777777 Don't know

8888888 Prefer not to say

[ASK IF Q13>0 AND IS NUMERIC]

Q14 What do you think is the likelihood that you will need help with any activities of daily living, including bathing, dressing, eating, walking across a room, and getting in or out of bed, for at least three years before you die?

[PN: PROVIDE BOX FOR NUMERICAL ANSWER] [RANGE: 0 - [RESPONSE TO Q11]]

Numeric

7777777 Don't know

8888888 Prefer not to say 


\section{Section 4: Preferences}

[PN: All calculated dollar values in this section are to be rounded to the nearest dollar and formatted as \$X,XXX in English and X XXX \$ in French]

Q15 Do you agree with the following statements?

[PN: ANSWERS: 5 Strongly Agree; 4 Agree; 3 Disagree; 2 Strongly Disagree; 1 Don't know] Q15a Parents should set aside money to leave to their children or heirs once they die, even when it means somewhat sacrificing their own comfort in retirement.

Q15b I prefer to live well but for fewer years than to live long and have to sacrifice my quality of life.

Q15c I would rather spend down my wealth quickly because I might not be healthy enough to enjoy the money later in life.

[Programming Note: Define INCOME_RISK as INCOME ROUNDED TO THE NEAREST 10,000. If INCOME<5,000, define INCOME_RISK as 10,000]

Q16 Please imagine you could choose between the two following situations.

Situation A: Your income is guaranteed to be [INCOME_RISK] per year for the rest of your life.

Situation B: There is a $50 \%$ chance your income will be [ $2 *$ INCOME_RISK] per year for the rest of your life and a $50 \%$ chance that it will be [(2/3)*INCOME_RISK] [PN: Please round this to the nearest 1,000] per year for the rest of your life.

Which situation would you prefer?

1 Situation $A$

2 Situation B

9999999 Don't know/refuse to answer

[PN: Ask if Q16==1]

Q16a Now please consider slightly different situations.

Situation A: Your income is guaranteed to be [INCOME_RISK] per year for the rest of your life.

Situation B: There is a $50 \%$ chance your income will be [2*INCOME_RISK] per year for the rest of your life and a $50 \%$ chance that it will be [(4/5)*INCOME_RISK] [PN: Please round this to the nearest 1,000] per year for the rest of your life.

Which situation would you prefer? 
1 Situation A

2 Situation B

9999999 Don't know/refuse to answer

[PN: Ask if Q16==2]

Q16b Now please consider slightly different situations.

Situation A: Your income is guaranteed to be INCOME_RISK per year for the rest of your life.

Situation B: There is a $50 \%$ chance your income will be [2*INCOME_RISK] per year for the rest of your life and a $50 \%$ chance that it will be [(1/2)*INCOME_RISK] [PN:

Please round this to the nearest 1,000] per year for the rest of your life.

Which situation would you prefer?

1 Situation A

2 Situation B

9999999 Don't know/refuse to answer 


\section{Section 8: On COVID-19}

In this last section, we will ask you a few questions about whether the COVID-19 pandemic has changed your perception about long-term care and your willingness to set aside money in case you should need care in the future.

Q27 Because of the COVID-19 pandemic, has your willingness to save for when you are older changed?

1 Yes, I am willing to save less

2 Yes, I am willing to save more

3 No

7777777 Don't know

8888888 Prefer not to say

[PN: Ask If Q27 == 2]

Q27a You told us that the COVID-19 pandemic has increased your willingness to save for when you are older. Is it because it increased your willingness to avoid going to a $\mathrm{NH}$ _SHORT if you need help with activities of daily living (ADLs)?

1 Yes

2 No

7777777 Don't know

8888888 Prefer not to say

Q28 Some companies offer insurance products, called long-term care insurance, to cover part of the costs of care for people who might need help with activities of daily living (ADLs) in the future. Have you ever thought about buying such product?

1 Yes

2 No

7777777 Don't know

8888888 Prefer not to say

[PN: Ask If Q28 == 1]

Q28a Has the COVID-19 pandemic changed your interest in such a product?

1 No

2 Yes, it has decreased my interest in such a product

3 Yes, it has increased my interest in such a product

7777777 Don't know

8888888 Prefer not to say

Q29 Imagine you will need help with activities of daily living ( $A D L S$ ) in the future. Would you say that because of the COVID-19 pandemic, you are 
1 More inclined to enter a NH_SHORT than before the pandemic.

2 Less inclined to enter a NH_SHORT than before the pandemic.

3 As inclined to enter a NH_SHORT as before the pandemic.

7777777 Don't know

8888888 Prefer not to say

Q30 Suppose the government were to propose a policy to increase the access to home care for people needing help with activities of daily living (ADLs) in order to reduce their likelihood of going to a NH_SHORT, but would increase taxes to finance this policy. What do you think would be your opinion about such a policy:

1 I would very much disagree with this plan.

2 I would disagree with this plan.

3 I would agree with this plan.

4 I would very much agree with this plan.

7777777 Don't know

8888888 Prefer not to say

[PN: Ask If Q30 IS NOT 7777777 and Q30 IS NOT 8888888]

[PN: SAME SCREEN AS Q30]

Q30a Has COVID-19 changed your appreciation about these types of policies?

1 No, it has not changed my view.

2 Yes, it has made me less favorable to these types of policies.

3 Yes, it has made me more favorable to these types of policies.

7777777 Don't know

8888888 Prefer not to say

Q31 Which of the statements below do you most agree with?

1 The recent COVID-19 epidemic did not change my view of exposure to health risks at public NH_SHORT2, in general.

2 The recent COVID-19 epidemic improved my view of exposure to health risks at public NH_SHORT2, in general.

3 The recent COVID-19 epidemic worsened my view of exposure to health risks at public $\mathrm{NH} \_$SHORT2, in general.

7777777 I have no opinion on this.

Q32 Which of the statements below do you most agree with?

1 The recent COVID-19 epidemic did not change my view of exposure to health risks at private NH_SHORT2, in general.

2 The recent COVID-19 epidemic improved my view of exposure to health risks at private $\mathrm{NH} \_$SHORT2, in general. 
3 The recent COVID-19 epidemic worsened my view of exposure to health risks at private NH_SHORT2, in general.

7777777 I have no opinion on this.

Q33 Which of the statements below do you most agree with?

1 I think that public and private NH_SHORT2 did equally well at managing the recent COVID-19 epidemic, in general.

2 I think that public NH_SHORT2 did better than private NH_SHORT2 at managing the recent COVID-19 epidemic, in general.

3 I think that public NH_SHORT2 did worse than private NH_SHORT2 at managing the recent COVID-19 epidemic, in general.

7777777 I have no opinion on this. 


\section{B Appendix: Additional results}

This section displays the results of the regressions with controls in Tables 4 to 6 with the estimates for the included control variables.

Our controls are:

- dummies for wealth (or net worth) quartile

- dummies for income quartiles

- dummies for risk aversion categories. The latter are measured using survey question for risk aversion based on the hypothetical income question from Barsky et al. (1997). The first category is the most risk averse while the fourth category is the most risk tolerant.

- a dummy for being female

- age

- a dummy for living in Quebec (other respondents are in Ontario)

- dummies for education (the default is having less than a high school diploma)

- dummies for marital status (the default is being married)

- a dummy for whether the respondent has at least one child

- a dummy for whether the respondent has at least one child living less than 20 kilometers away

- the number of diagnosed health problems

- dummies for work status (the default is working)

Table B.1 corresponds to Table 4 in the main text but shows the estimates for our control variables.

Table B.2 shows all the marginal effects for the regression in Column (2) of Table 5 in the main text.

Table B.3 shows all the marginal effects for the regression in Column (4) of Table 5 in the main text.

Table B.4 shows all the marginal effects for the regression in Column (2) of Table 6 in the main text.

Table B.5 shows all the marginal effects for the regression in Column (4) of Table 6 in the main text. 
Table B.1: Nursing home aversion and saving for older ages

\begin{tabular}{|c|c|c|c|c|c|c|}
\hline & $(1)$ & \multicolumn{2}{|l|}{ (2) } & $(3)$ & \multicolumn{2}{|c|}{ (4) } \\
\hline less inclined NH & $0.085^{* * *} \quad(0.028)$ & $0.105^{* * *}$ & $(0.027)$ & $0.112^{* * *} \quad(0.019)$ & $0.140^{* * *}$ & $(0.020)$ \\
\hline wealth quartile & & & & & & \\
\hline 2nd & & -0.029 & $(0.042)$ & & -0.006 & $(0.033)$ \\
\hline 3rd & & -0.022 & $(0.042)$ & & -0.019 & $(0.032)$ \\
\hline 4 th & & -0.039 & $(0.045)$ & & -0.039 & $(0.033)$ \\
\hline income quartile & & & & & & \\
\hline 2nd 2 & & 0.002 & $(0.039)$ & & 0.019 & $(0.029)$ \\
\hline 3rd & & -0.028 & $(0.039)$ & & -0.012 & $(0.029)$ \\
\hline 4 th & & -0.013 & $(0.042)$ & & -0.007 & $(0.031)$ \\
\hline risk category & & & & & & \\
\hline 2nd & & -0.047 & $(0.029)$ & & -0.030 & $(0.022)$ \\
\hline $3 r d$ & & -0.019 & $(0.042)$ & & -0.014 & $(0.031)$ \\
\hline 4 th & & 0.025 & $(0.045)$ & & 0.019 & $(0.034)$ \\
\hline female & & 0.026 & $(0.026)$ & & 0.016 & $(0.020)$ \\
\hline age & & -0.004 & $(0.003)$ & & $-0.005^{* *}$ & $(0.002)$ \\
\hline Quebec province & & $-0.075^{* * *}$ & $(0.026)$ & & $-0.082^{* * *}$ & $(0.020)$ \\
\hline $\begin{array}{l}\text { education (wrt }<\text { high school) } \\
\text { high school }\end{array}$ & & -0.061 & $(0.084)$ & & -0.064 & $(0.078)$ \\
\hline trade & & -0.072 & $(0.089)$ & & -0.085 & $(0.081)$ \\
\hline college & & -0.047 & $(0.084)$ & & -0.054 & $(0.077)$ \\
\hline some undergrad. & & -0.016 & $(0.091)$ & & -0.041 & $(0.082)$ \\
\hline undergrad. & & -0.050 & $(0.085)$ & & -0.051 & $(0.077)$ \\
\hline grad. & & -0.027 & $(0.087)$ & & -0.063 & $(0.078)$ \\
\hline marital status (wrt married) & & & & & & \\
\hline common-law & & 0.024 & $(0.037)$ & & -0.004 & $(0.027)$ \\
\hline widowed & & 0.064 & $(0.062)$ & & 0.051 & $(0.051)$ \\
\hline separated & & 0.036 & $(0.076)$ & & 0.014 & $(0.052)$ \\
\hline divorced & & 0.033 & $(0.044)$ & & 0.041 & $(0.033)$ \\
\hline never married & & 0.046 & $(0.044)$ & & 0.027 & $(0.033)$ \\
\hline has a child & & -0.036 & $(0.036)$ & & -0.021 & $(0.028)$ \\
\hline has a child $<20 \mathrm{~km}$ & & $0.067 * *$ & $(0.031)$ & & $0.045^{*}$ & $(0.024)$ \\
\hline \# health problems & & $0.023^{*}$ & $(0.014)$ & & $0.022^{* *}$ & $(0.011)$ \\
\hline work status (wrt working ) & & $120 * * *$ & $(0028)$ & & $122 * * *$ & $(0020)$ \\
\hline retired & & -0.130 & $\begin{aligned}(0.020) \\
(0.089)\end{aligned}$ & & $\begin{array}{l}-0.132^{* a+1}-10 \\
-0.046\end{array}$ & $\begin{array}{l}(0.023) \\
(0.068)\end{array}$ \\
\hline not working & & $-0.211^{* * *}$ & $(0.049)$ & & $-0.153 * * *$ & $(0.046)$ \\
\hline constant & $0.222^{* * *} \quad(0.023)$ & $0.569 * * *$ & $(0.191)$ & $0.180^{* * *}$ & $0.595^{* * *}$ & $(0.148)$ \\
\hline Use sampling weights & $\mathrm{Y}$ & $\mathrm{Y}$ & & $\mathrm{N}$ & $\mathrm{N}$ & \\
\hline Observations & 2374 & 2261 & & 2374 & 22 & \\
\hline$R^{2}$ & 0.007 & 0.06 & & 0.012 & 0.0 & \\
\hline Adjusted $R^{2}$ & 0.007 & 0.04 & & 0.012 & 0.0 & \\
\hline
\end{tabular}

Notes: This table presents OLS regression results where the dependent variable is whether respondent plans to save more due to the pandemic. Robust standard errors are in parentheses. See the text for the control variables included.

$*$, **, ***: significant at $10 \%, 5 \%$ and $1 \%$ level respectively. 
Table B.2: Support for home-care subsidy (with controls and weights)

\begin{tabular}{|c|c|c|c|c|c|c|c|c|}
\hline \multirow{2}{*}{ less inclined $\mathrm{NH}$} & \multicolumn{2}{|c|}{ very much disagree } & \multicolumn{2}{|c|}{ disagree } & \multicolumn{2}{|c|}{ agree } & \multicolumn{2}{|c|}{ very much agree } \\
\hline & 0.0123 & $(0.0187)$ & -0.0334 & $(0.0255)$ & $-0.0789 * *$ & $(0.0319)$ & $0.1001^{* * *}$ & $(0.0271)$ \\
\hline 2nd & $-0.0672 *$ & $(0.0343)$ & -0.0255 & $(0.0367)$ & $0.1036^{* *}$ & $(0.0459)$ & -0.0108 & $(0.0369)$ \\
\hline $3 \mathrm{rd}$ & -0.0577 & $(0.0360)$ & 0.0132 & $(0.0388)$ & 0.0736 & $(0.0454)$ & -0.0291 & $(0.0353)$ \\
\hline 4 th & $-0.0940 * * *$ & $(0.0352)$ & -0.0291 & $(0.0384)$ & $0.1142^{* *}$ & $(0.0480)$ & 0.0090 & $(0.0431)$ \\
\hline \multicolumn{9}{|l|}{ income quartile } \\
\hline 2nd & 0.0081 & $(0.0213)$ & -0.0055 & $(0.0371)$ & 0.0212 & $(0.0439)$ & -0.0238 & $(0.0363)$ \\
\hline $3 \mathrm{rd}$ & 0.0365 & $(0.0269)$ & -0.0349 & $(0.0349)$ & 0.0374 & $(0.0430)$ & -0.0391 & $(0.0373)$ \\
\hline 4 th & $0.0693^{* *}$ & $(0.0278)$ & -0.0411 & $(0.0367)$ & 0.0372 & $(0.0466)$ & $-0.0655^{*}$ & $(0.0364)$ \\
\hline \multicolumn{9}{|l|}{ risk category } \\
\hline 2nd & -0.0025 & $(0.0216)$ & -0.0420 & $(0.0275)$ & 0.0433 & $(0.0341)$ & 0.0012 & $(0.0257)$ \\
\hline $3 \mathrm{rd}$ & 0.0461 & $(0.0333)$ & $-0.0599 *$ & $(0.0360)$ & 0.0141 & $(0.0444)$ & -0.0004 & $(0.0388)$ \\
\hline 4 th & -0.0031 & $(0.0284)$ & -0.0119 & $(0.0399)$ & 0.0233 & $(0.0479)$ & -0.0084 & $(0.0376)$ \\
\hline female & -0.0206 & $(0.0181)$ & -0.0156 & $(0.0235)$ & 0.0337 & $(0.0289)$ & 0.0025 & $(0.0228)$ \\
\hline age & -0.0025 & $(0.0020)$ & -0.0007 & $(0.0028)$ & -0.0012 & $(0.0032)$ & $0.0043^{*}$ & $(0.0025)$ \\
\hline Quebec & -0.0004 & $(0.0183)$ & $-0.0827 * * *$ & $(0.0253)$ & 0.0176 & $(0.0291)$ & $0.0655 * * *$ & $(0.0222)$ \\
\hline education (wrt $<$ high school) & & & & & & & & \\
\hline high school & $-0.1232^{*}$ & $(0.0715)$ & 0.0148 & $(0.0738)$ & $0.1542^{*}$ & $(0.0872)$ & -0.0458 & $(0.0752)$ \\
\hline trade & -0.0972 & $(0.0756)$ & 0.0040 & $(0.0788)$ & 0.1371 & $(0.0932)$ & -0.0439 & $(0.0792)$ \\
\hline college & -0.0877 & $(0.0730)$ & -0.0028 & $(0.0729)$ & 0.1233 & $(0.0859)$ & -0.0327 & $(0.0753)$ \\
\hline some undergrad. & -0.1129 & $(0.0764)$ & -0.0465 & $(0.0778)$ & $0.1699^{*}$ & $(0.0949)$ & -0.0105 & $(0.0818)$ \\
\hline undergrad. & $-0.1226^{*}$ & $(0.0728)$ & -0.0560 & $(0.0725)$ & 0.1409 & $(0.0864)$ & 0.0377 & $(0.0775)$ \\
\hline grad. & $-0.1247^{*}$ & $(0.0734)$ & -0.0814 & $(0.0740)$ & 0.1250 & $(0.0886)$ & 0.0812 & $(0.0798)$ \\
\hline \multicolumn{9}{|l|}{ marital status (wrt married) } \\
\hline common law & 0.0046 & $(0.0317)$ & -0.0011 & $(0.0366)$ & -0.0141 & $(0.0430)$ & 0.0106 & $(0.0326)$ \\
\hline widowed & 0.0523 & $(0.0529)$ & -0.0425 & $(0.0540)$ & -0.0241 & $(0.0717)$ & 0.0143 & $(0.0590)$ \\
\hline separated & 0.0420 & $(0.0560)$ & $-0.1648 * * *$ & $(0.0290)$ & 0.0935 & $(0.0713)$ & 0.0293 & $(0.0576)$ \\
\hline divorced & $-0.0445^{*}$ & $(0.0239)$ & -0.0421 & $(0.0388)$ & 0.0574 & $(0.0488)$ & 0.0292 & $(0.0377)$ \\
\hline never married & -0.0365 & $(0.0237)$ & 0.0146 & $(0.0433)$ & -0.0036 & $(0.0502)$ & 0.0256 & $(0.0433)$ \\
\hline has child & 0.0375 & $(0.0260)$ & 0.0113 & $(0.0366)$ & 0.0268 & $(0.0447)$ & $-0.0755^{* *}$ & $(0.0343)$ \\
\hline has child $<20 \mathrm{~km}$ & -0.0265 & $(0.0238)$ & -0.0158 & $(0.0303)$ & -0.0009 & $(0.0377)$ & 0.0431 & $(0.0294)$ \\
\hline \# health problems & -0.0073 & $(0.0115)$ & -0.0120 & $(0.0127)$ & -0.0005 & $(0.0154)$ & $0.0198^{*}$ & $(0.0117)$ \\
\hline work status (wrt working) & -0.0030 & $(0.0213)$ & 0.0240 & $(0.0305)$ & $0.0611^{*}$ & & $-0.0820 * * *$ & $(0.0241)$ \\
\hline looking for work & 0.0344 & $(0.0652)$ & 0.1047 & $(0.0892)$ & -0.0005 & $(0.0925)$ & $-0.1386^{* *}$ & $(0.0572)$ \\
\hline not working & 0.0342 & $(0.0431)$ & -0.0434 & $(0.0480)$ & 0.0012 & $(0.0670)$ & 0.0080 & $(0.0707)$ \\
\hline
\end{tabular}

Notes: This table presents the average marginal effects of all the variables used on being in each category of support for a policy that subsidizes home care, estimated from multinomial logit regressions. Sampling weights are used. Robust standard errors are in parentheses.

$*, * *, * * *$ : significant at $10 \%, 5 \%$ and $1 \%$ level respectively. 
Table B.3: Support for home-care subsidy (with controls and without weights)

\begin{tabular}{|c|c|c|c|c|c|c|c|c|}
\hline \multirow{2}{*}{ less inclined $\mathrm{NH}$} & \multicolumn{2}{|c|}{ very much disagree } & \multicolumn{2}{|c|}{ disagree } & \multicolumn{2}{|c|}{ agree } & \multicolumn{2}{|c|}{ very much agree } \\
\hline & 0.0029 & $(0.0154)$ & -0.0089 & $(0.0190)$ & $-0.0673^{* * *}$ & $(0.0252)$ & $0.0732 * * *$ & $(0.0231)$ \\
\hline 2nd & $-0.0782^{* * *}$ & $(0.0277)$ & -0.0128 & $(0.0281)$ & $0.0877^{* *}$ & $(0.0370)$ & 0.0032 & $(0.0319)$ \\
\hline 3rd & $-0.0744^{* * *}$ & $(0.0280)$ & -0.0004 & $(0.0283)$ & $0.0779 * *$ & $(0.0364)$ & -0.0031 & $(0.0312)$ \\
\hline 4 th & $-0.0758 * * *$ & $(0.0288)$ & -0.0111 & $(0.0295)$ & $0.0924^{* *}$ & $(0.0378)$ & -0.0055 & $(0.0328)$ \\
\hline income quartile & & & & & & & & \\
\hline 2nd & 0.0147 & $(0.0192)$ & 0.0048 & $(0.0268)$ & 0.0064 & $(0.0347)$ & -0.0259 & $(0.0309)$ \\
\hline 3rd & 0.0135 & $(0.0196)$ & -0.0118 & $(0.0257)$ & 0.0510 & $(0.0344)$ & $-0.0527^{*}$ & $(0.0304)$ \\
\hline 4 th & $0.0497^{* *}$ & $(0.0210)$ & -0.0215 & $(0.0271)$ & 0.0182 & $(0.0368)$ & -0.0464 & $(0.0324)$ \\
\hline risk category & & & & & & & & \\
\hline 2nd & -0.0225 & $(0.0153)$ & -0.0293 & $(0.0201)$ & $0.0529 * *$ & $(0.0268)$ & -0.0010 & $(0.0229)$ \\
\hline $3 r d$ & 0.0255 & $(0.0246)$ & -0.0261 & $(0.0276)$ & 0.0364 & $(0.0363)$ & -0.0358 & $(0.0299)$ \\
\hline 4 th & 0.0057 & $(0.0244)$ & -0.0019 & $(0.0314)$ & 0.0215 & $(0.0397)$ & -0.0253 & $(0.0318)$ \\
\hline female & -0.0225 & $(0.0145)$ & 0.0080 & $(0.0175)$ & 0.0333 & $(0.0234)$ & -0.0188 & $(0.0202)$ \\
\hline age & -0.0019 & $(0.0015)$ & -0.0004 & $(0.0018)$ & -0.0034 & $(0.0025)$ & $0.0057^{* * *}$ & $(0.0021)$ \\
\hline Quebec & 0.0053 & $(0.0139)$ & $-0.0584^{* * *}$ & $(0.0184)$ & 0.0029 & $(0.0233)$ & $0.0502^{* *}$ & $(0.0198)$ \\
\hline education (wrt $<$ high school) & & & & & & & & \\
\hline high school & -0.0947 & $(0.0695)$ & 0.0455 & $(0.0689)$ & 0.1047 & $(0.0892)$ & -0.0556 & $(0.0745)$ \\
\hline trade & -0.0788 & $(0.0721)$ & 0.0043 & $(0.0720)$ & 0.1388 & $(0.0934)$ & -0.0643 & $(0.0768)$ \\
\hline college & -0.0788 & $(0.0696)$ & 0.0031 & $(0.0673)$ & 0.0864 & $(0.0877)$ & -0.0106 & $(0.0741)$ \\
\hline some undergrad. & -0.0959 & $(0.0730)$ & -0.0056 & $(0.0732)$ & 0.1002 & $(0.0950)$ & 0.0013 & $(0.0801)$ \\
\hline undergrad. & -0.1031 & $(0.0696)$ & -0.0442 & $(0.0672)$ & 0.0914 & $(0.0879)$ & 0.0559 & $(0.0749)$ \\
\hline grad. & -0.0998 & $(0.0702)$ & -0.0506 & $(0.0688)$ & 0.0725 & $(0.0898)$ & 0.0779 & $(0.0769)$ \\
\hline marital status (wrt married) & & & & & & & & \\
\hline common law & 0.0006 & $(0.0211)$ & 0.0093 & $(0.0277)$ & -0.0277 & $(0.0334)$ & 0.0178 & $(0.0283)$ \\
\hline widowed & 0.0303 & $(0.0405)$ & -0.0165 & $(0.0439)$ & -0.0517 & $(0.0601)$ & 0.0380 & $(0.0518)$ \\
\hline separated & 0.0288 & $(0.0403)$ & $-0.1062^{* * *}$ & $(0.0353)$ & 0.0331 & $(0.0614)$ & 0.0443 & $(0.0557)$ \\
\hline divorced & -0.0228 & $(0.0211)$ & -0.0336 & $(0.0270)$ & 0.0374 & $(0.0376)$ & 0.0190 & $(0.0323)$ \\
\hline never married & -0.0018 & $(0.0235)$ & -0.0059 & $(0.0302)$ & -0.0019 & $(0.0387)$ & 0.0097 & $(0.0318)$ \\
\hline has child & 0.0196 & $(0.0210)$ & 0.0322 & $(0.0272)$ & -0.0088 & $(0.0350)$ & -0.0430 & $(0.0293)$ \\
\hline has child $<20 \mathrm{~km}$ & -0.0077 & $(0.0183)$ & -0.0088 & $(0.0223)$ & -0.0131 & $(0.0299)$ & 0.0295 & $(0.0260)$ \\
\hline \# health problems & -0.0044 & $(0.0078)$ & -0.0082 & $(0.0093)$ & -0.0076 & $(0.0123)$ & $0.0202^{*}$ & $(0.0105)$ \\
\hline work status (wrt working) & & & م0120 م- & & $00752 * * *$ & & $00520 * *$ & \\
\hline looking for work & 0.0089 & $(0.0480)$ & 0.0439 & $(0.0640)$ & 0.0349 & $(0.0773)$ & -0.0877 & $(0.0618)$ \\
\hline not working & 0.0210 & $(0.0359)$ & -0.0119 & $(0.0408)$ & 0.0390 & $(0.0539)$ & -0.0480 & $(0.0471)$ \\
\hline
\end{tabular}

Notes: This table presents the average marginal effects of all the variables used on being in each category of support for a policy that subsidizes home care, estimated from multinomial logit regressions. Sampling weights are not used. Robust standard errors are in parentheses.

$*, * *, * * *$ : significant at $10 \%, 5 \%$ and $1 \%$ level respectively. 
Table B.4: Change in the support for home-care subsidy (with controls and weights)

\begin{tabular}{|c|c|c|c|c|c|c|}
\hline \multirow[b]{2}{*}{$\begin{array}{l}\text { less inclined NH } \\
\text { wealth guartile }\end{array}$} & \multicolumn{2}{|c|}{ no change } & \multicolumn{2}{|c|}{ less in favor } & \multicolumn{2}{|c|}{ more in favor } \\
\hline & $-0.3369^{* * *}$ & $(0.0269)$ & $0.0994^{* * *}$ & $(0.0273)$ & $0.2374^{* * *}$ & $(0.0321)$ \\
\hline 2nd & -0.0167 & $(0.0470)$ & $-0.0688^{* *}$ & $(0.0338)$ & $0.0855^{*}$ & $(0.0450)$ \\
\hline $3 r d$ & -0.0237 & $(0.0451)$ & -0.0510 & $(0.0355)$ & $0.0747^{*}$ & $(0.0439)$ \\
\hline 4th & -0.0721 & $(0.0467)$ & $-0.0675^{* *}$ & $(0.0342)$ & $0.1395 * * *$ & $(0.0464)$ \\
\hline income quartile & & & & & & \\
\hline 2nd & 0.0027 & $(0.0432)$ & 0.0011 & $(0.0300)$ & -0.0037 & $(0.0444)$ \\
\hline $3 r d$ & 0.0077 & $(0.0408)$ & 0.0206 & $(0.0313)$ & -0.0283 & $(0.0424)$ \\
\hline 4 th & $0.1073^{* *}$ & $(0.0438)$ & -0.0274 & $(0.0278)$ & $-0.0799^{*}$ & $(0.0439)$ \\
\hline risk category & & & & & & \\
\hline 2nd & -0.0229 & $(0.0325)$ & -0.0128 & $(0.0230)$ & 0.0357 & $(0.0330)$ \\
\hline $3 \mathrm{rd}$ & 0.0107 & $(0.0434)$ & -0.0312 & $(0.0279)$ & 0.0206 & $(0.0449)$ \\
\hline 4 th & -0.0320 & $(0.0521)$ & 0.0010 & $(0.0370)$ & 0.0310 & $(0.0493)$ \\
\hline female & -0.0255 & $(0.0285)$ & -0.0129 & $(0.0195)$ & 0.0384 & $(0.0283)$ \\
\hline age & 0.0029 & $(0.00$ & -0.0027 & $(0.0023)$ & -0.0001 & $(0.0029)$ \\
\hline $\begin{array}{l}\text { Quebec } \\
\text { education (wrt < high school) }\end{array}$ & $0.0836^{* * *}$ & $(0.0281)$ & $-0.0661^{* * *}$ & $(0.0215)$ & -0.0176 & $(0.0286)$ \\
\hline high sc & -0.1347 & $(0.0901)$ & -0.0472 & $(0.0665)$ & $0.1820^{* *}$ & $(0.0805)$ \\
\hline trade & -0.0555 & $(0.0951)$ & -0.0758 & $(0.0703)$ & 0.1313 & $(0.0839)$ \\
\hline college & -0.1244 & $(0.0886)$ & -0.0196 & $(0.0677)$ & $0.1440^{*}$ & $(0.0785)$ \\
\hline some undergrad. & $-0.1796^{*}$ & $(0.0956)$ & -0.0584 & $(0.0716)$ & $0.2381^{* * *}$ & $(0.0884)$ \\
\hline undergrad. & -0.1289 & $(0.0887)$ & -0.0504 & $(0.0671)$ & $0.1793^{* *}$ & $(0.0794)$ \\
\hline grad. & $-0.1776^{* *}$ & $(0.0904)$ & -0.0866 & $(0.0674)$ & $0.2642^{* * *}$ & $(0.0812)$ \\
\hline marital status (wrt married) & & & & & & \\
\hline common law & -0.0322 & $(0.0416)$ & 0.0337 & $(0.0367)$ & -0.0015 & $(0.0411)$ \\
\hline widowed & 0.0285 & $(0.0714)$ & $-0.0605^{*}$ & $(0.0365)$ & 0.0321 & $(0.0731)$ \\
\hline separated & -0.0224 & $(0.0634)$ & -0.0253 & $(0.0478)$ & 0.0477 & $(0.0689)$ \\
\hline divorced & 0.0745 & $(0.0470)$ & $-0.0537^{* *}$ & $(0.0256)$ & -0.0208 & $(0.0463)$ \\
\hline never $\mathrm{n}$ & 0035 & $(0.05$ & -0.0304 & $(0.0321)$ & 0.0269 & $(0.0502)$ \\
\hline has child & 0.0599 & $(0.0430)$ & 0.0049 & $(0.0313)$ & -0.0649 & $(0.0420)$ \\
\hline has child $<20 \mathrm{~km}$ & $-0.0616^{*}$ & $(0.0360)$ & 0.0021 & $(0.0246)$ & 0.0595 & $(0.0364)$ \\
\hline \# health problems & -0.0183 & $(0.0148)$ & -0.0012 & $(0.0107)$ & 0.0195 & $(0.0149)$ \\
\hline retired & 0.0061 & $(0.034$ & 0.0021 & $(0.0282)$ & -0.0082 & $(0.0330)$ \\
\hline looking for work & -0.0590 & $(0.0757)$ & 0.0865 & $(0.0772)$ & -0.0275 & $(0.0882)$ \\
\hline not working & -0.0021 & $(0.0704)$ & $-0.0675^{* *}$ & $(0.0271)$ & 0.0696 & $(0.0718)$ \\
\hline
\end{tabular}

Notes: This table presents the average marginal effects of all the variables on being in each category of change in the support for a policy that subsidizes home care, estimated from multinomial logit regressions. Sampling weights are used. Robust standard errors are in parentheses. See the text for the control variables included.

$*, * *, * * *$ : significant at $10 \%, 5 \%$ and $1 \%$ level respectively. 
Table B.5: Change in the support for home-care subsidy (with controls and without weights)

\begin{tabular}{|c|c|c|c|c|c|c|}
\hline \multirow{2}{*}{$\begin{array}{l}\text { less inclined NH } \\
\text { wealth quartile }\end{array}$} & \multicolumn{2}{|c|}{ no change } & \multicolumn{2}{|c|}{ less in favor } & \multicolumn{2}{|c|}{ more in favor } \\
\hline & $-0.3540^{* * *}$ & $(0.0219)$ & $0.0938 * * *$ & $(0.0206)$ & $0.2602^{* * *}$ & $(0.0261)$ \\
\hline 2nd & -0.0417 & $(0.0376)$ & -0.0409 & $(0.0252)$ & $0.0826 * *$ & $(0.0371)$ \\
\hline 3rd & -0.0198 & $(0.0373)$ & $-0.0432^{*}$ & $(0.0246)$ & $0.0630^{*}$ & $(0.0365)$ \\
\hline 4 th & -0.0582 & $(0.0382)$ & -0.0302 & $(0.0257)$ & $0.0884^{* *}$ & $(0.0377)$ \\
\hline \multicolumn{7}{|l|}{ income quartile } \\
\hline 2nd & -0.0027 & $(0.0343)$ & 0.0019 & $(0.0234)$ & 0.0008 & $(0.0348)$ \\
\hline $3 \mathrm{rd}$ & -0.0076 & $(0.0337)$ & 0.0106 & $(0.0228)$ & -0.0029 & $(0.0344)$ \\
\hline 4 th & 0.0467 & $(0.0364)$ & -0.0230 & $(0.0218)$ & -0.0238 & $(0.0364)$ \\
\hline \multicolumn{7}{|l|}{ risk category } \\
\hline 2nd & $-0.0532^{* *}$ & $(0.0254)$ & -0.0131 & $(0.0163)$ & $0.0663^{* *}$ & $(0.0262)$ \\
\hline 3rd & -0.0045 & $(0.0351)$ & -0.0211 & $(0.0214)$ & 0.0256 & $(0.0354)$ \\
\hline 4 th & -0.0476 & $(0.0414)$ & 0.0261 & $(0.0288)$ & 0.0215 & $(0.0407)$ \\
\hline female & -0.0157 & $(0.0230)$ & -0.0104 & $(0.0149)$ & 0.0261 & $(0.0232)$ \\
\hline age & $0.0049^{* *}$ & $(0.0024)$ & $-0.0026^{*}$ & $(0.0015)$ & -0.0023 & $(0.0024)$ \\
\hline Quebec & $0.0951^{* * *}$ & $(0.0225)$ & $-0.0433^{* * *}$ & $(0.0152)$ & $-0.0519 * *$ & $(0.0229)$ \\
\hline \multicolumn{7}{|l|}{ education (wrt < high school) } \\
\hline high school & -0.1184 & $(0.0934)$ & -0.0373 & $(0.0699)$ & $0.1557^{*}$ & $(0.0807)$ \\
\hline trade & -0.0757 & $(0.0979)$ & -0.0650 & $(0.0722)$ & $0.1407^{*}$ & $(0.0846)$ \\
\hline college & -0.1009 & $(0.0918)$ & -0.0230 & $(0.0697)$ & 0.1239 & $(0.0784)$ \\
\hline some undergrad. & -0.1530 & $(0.0980)$ & -0.0464 & $(0.0733)$ & $0.1994^{* *}$ & $(0.0865)$ \\
\hline undergrad. & -0.0980 & $(0.0918)$ & -0.0657 & $(0.0691)$ & $0.1637^{* *}$ & $(0.0786)$ \\
\hline grad. & -0.1364 & $(0.0933)$ & -0.0846 & $(0.0696)$ & $0.2210^{* * *}$ & $(0.0803)$ \\
\hline \multicolumn{7}{|l|}{ marital status (wrt married) } \\
\hline common law & 0.0030 & $(0.0333)$ & 0.0049 & $(0.0227)$ & -0.0079 & $(0.0335)$ \\
\hline widowed & 0.0063 & $(0.0557)$ & -0.0266 & $(0.0354)$ & 0.0203 & $(0.0585)$ \\
\hline separated & -0.0536 & $(0.0555)$ & 0.0114 & $(0.0430)$ & 0.0423 & $(0.0584)$ \\
\hline divorced & 0.0214 & $(0.0372)$ & -0.0131 & $(0.0226)$ & -0.0083 & $(0.0369)$ \\
\hline never married & -0.0058 & $(0.0392)$ & -0.0146 & $(0.0235)$ & 0.0204 & $(0.0387)$ \\
\hline has child & 0.0304 & $(0.0342)$ & 0.0062 & $(0.0219)$ & -0.0367 & $(0.0343)$ \\
\hline has child $<20 \mathrm{~km}$ & -0.0395 & $(0.0289)$ & 0.0149 & $(0.0187)$ & 0.0247 & $(0.0295)$ \\
\hline \# health problems & $-0.0304^{* * *}$ & $(0.0117)$ & 0.0052 & $(0.0075)$ & $0.0252^{* *}$ & $(0.0119)$ \\
\hline retired & -0.0017 & $(0.0268)$ & -0.0228 & $(0.0168)$ & 0.0245 & $(0.0271)$ \\
\hline looking for work & -0.0428 & $(0.0750)$ & 0.0455 & $(0.0560)$ & -0.0027 & $(0.0780)$ \\
\hline not working & -0.0173 & $(0.0580)$ & -0.0113 & $(0.0357)$ & 0.0286 & $(0.0569)$ \\
\hline
\end{tabular}

Notes: This table presents the average marginal effects of all the variables on being in each category of change in the support for a policy that subsidizes home care, estimated from multinomial logit regressions. Sampling weights are not used. Robust standard errors are in parentheses. See the text for the control variables included.

$*, * *, * * *$ : significant at $10 \%, 5 \%$ and $1 \%$ level respectively. 